\title{
Design, synthesis and pharmacological screening of $\beta$-amino-, thiadiazole/thiadiazine-phosphonate based triazole motifs as antimicrobial/cytotoxic agents
}

WAFAA M. ABDOU*
NEVEN A. GANOUB
EMAN SABRY

Chemical Industries Division

National Research Centre

D-12311, Dokki

Cairo, Egypt

Accepted April 30, 2014

\begin{abstract}
Three different series of phosphonate derivatives, $\beta$-aminoand fused thiadiazolo/thiadiazine-phosphonates have been synthesized using the addition and/or addition-cyclization protocol of Horner-Wadsworth-Emmons (HWE) reagents to 1,2,4-triazole-3-thiols. The design of potentially antimicrobial and anticancer phosphor esters relied on the results of computer-assisted molecular modeling. All synthesized phosphonates were evaluated for their in vitro antimicrobial activities while anticancer properties were determined for eight out of twenty new phosphonates. The tested phosphonates, except for compounds that have a nitrile moiety, exhibited moderate to significant antimicrobial activity. Nevertheless, the most active compounds were fused thiadiazole-phosphonates, which inhibited the growth of both Gram-negative and Gram-positive bacteria better than $\beta$-aminophosphonates and fused thiadiazolophosphonates. In parallel, the antitumor activity screenings of selected phosphonates from each series and substrate $\mathbf{1}$ were also done. Their antitumor properties against ten carcinoma cell lines, including breast (MCF7, MDA-MB- 231/ ATCC, MDA-MB-435, BT-549), ovarian (IGROVI, OVCAR-3, SK-OV-3), prostate (PX-3, PU-145), and liver (HEPG2), were investigated. The results showed that all synthesized compounds reflected remarkable antitumor activity against breast (especially MDA-MB-231/ATCC and BT-549), and prostate carcinoma cell lines (PC-3 and DU-145), whereas a moderate to good effect on ovarian and liver cancer cells was observed.
\end{abstract}

Keywords: $\beta$-amino/thiadiazolo/thiadiazino-phosphonates, 1,2,4-triazole-3-thiols, Horner-Wadsworth-Emmons reagents, in vitro antimicrobial/antineoplastic activity

The alarming rates of growing antibiotic resistance are major threats to public health and scientific communities worldwide, especially in the field of multidrug-resistant bacte-

\footnotetext{
* Correspondence; e-mail: wabdou@link.net
} 
ria and fungi (1). In addition, cancer is among the most critical health issues and is considered to be the second leading cause of death, just after circulatory diseases. Despite the availability of improved drugs, including targeted cancer therapies, according to the World Health Organization (WHO), the worldwide cancer burden is expected to increase by as much as $50 \%$ by the year 2020 unless further preventive measures are put into practice (2). These trends have emphasized the urgent need for new, more effective and safe antimicrobial and/or antitumor drugs that may have dual/multiple action towards biological targets $(3,4)$.

Chemistry of $N$-bridged heterocyclic compounds, such as triazoles, especially 1,2,4-triazoles, has received considerable attention in recent years due to their biological activities. However, a number of biological activities such as antiinflammatory, analgesic and others are associated with the $\mathrm{N}$-substituted 1,2,4-triazole nucleus attached with different heterocycles $(5,6)$. Furthermore, over the last two decades, a continuous trend is observed toward the chemistry of $N, P$-heterocycles and derived phosphonates, largely, because these compounds tend to have high antibiotic (7) and antitumor potencies (8). Moreover, the 1,2,4-triazole nucleus has been incorporated into a wide variety of therapeutically important agents. Ribavirin, posaconazole, fluconazole and itraconazole are efficient antibacterial and/or antifungal drugs used in current treatments (9). Further, vorozole, letrozole and anastrozole are some examples of antitumor drugs containing the 1,2,4-triazole moiety (10). In view of these observations and our program of synthesis of 5-membered $N$-heterocycle phosphor esters with antibiotic (11-13) and anticancer properties (14-16), we report herein the synthesis of three series of $\beta$-amino-, fused thiadiazolo-, and thiadiazino-phosphonate-based 1,2,4-triazole motifs. Optimized antimicrobial and cytotoxic activity of newly-synthesized phosphonates was based on potency prediction using the computerassisted molecular modeling (CAMM) $(17,18)$.

\section{EXPERIMENTAL}

\section{General}

Melting points were determined with an open capillary tube on an Electrothermal (variable heater, Stuart, UK) melting point apparatus and were corrected. IR spectra were recorded on a JASCO FT-IR 6100 using a KBr disc (JASCO, Japan). NMR spectra were measured with a JEOL E.C.A-500 MHz ( $\left.{ }^{13} \mathrm{C}: 125.4 \mathrm{MHz},{ }^{1} \mathrm{H}: 500.7 \mathrm{MHz},{ }^{31} \mathrm{P}: 200.7 \mathrm{MHz}\right)$ spectrometer (JEOL, Japan). ${ }^{31} \mathrm{P}$ NMR spectra were recorded with $\mathrm{H}_{3} \mathrm{PO}_{4}(85 \%)$ as external reference, ${ }^{1} \mathrm{H}$ and ${ }^{13} \mathrm{C}$ NMR spectra were recorded with trimethylsilane as internal standard in $\mathrm{CDCl}_{3}$. Chemical shifts $(\delta)$ are given in ppm. Mass spectra were recorded at $70 \mathrm{eV}$ on an MS-50 Kratos (A.E.I.) spectrometer (Kratos, UK). Elemental analyses were carried out at the Microanalysis Laboratory, Cairo University. Elemental analyses were performed using elementary Analysensysteme GmbH-vario EL III Element Analyzer (Germany). Compounds 4-(4-(dimethylamino)benzylideneamino)-4H-1,2,4-triazole-3-thiol (1) and 4-(4-chlorobenzylidene-amino)-4H-1,2,4-triazole-3-thiol (2) were obtained using the procedures reported elsewhere $(19,20)$. Phosphonyl carbanion reagents: [diethyl (2-amino-2thioxoethyl)-, diethyl cyanomethylphosphonate, methyl diethyl-, triethyl phosphonoacetate, diethyl (methylthiomethyl)phosphonates, diethyl (methylthioethyl)phosphonate and diethyl 2-methylallylphosphonate] were purchased from Sigma-Aldrich Company (USA). 
W. M. Abdou et al.: Design, synthesis and pharmacological screening of $\beta$-amino-, thiadiazole/thiadiazine-phosphonate based triazole motifs as antimicrobial/cytotoxic agents, Acta Pharm. 64 (2014) 267-284.

\section{General synthesis procedure}

Synthesis of $3 \boldsymbol{a}$ - $\boldsymbol{h}$ and $\mathbf{4} \boldsymbol{a}-\boldsymbol{h}$. - A solution of $\mathrm{LiH}(0.1 \mathrm{~g}, 12.6 \mathrm{mmol})$ in DMF $(20 \mathrm{~mL})$ and the phosphonyl carbanion $(4.2 \mathrm{mmol})$ [diethyl (2-amino-2-thioxoethyl)-, diethyl cyanomethylphosphonate, methyl diethyl- or triethyl phosphonoacetate] was stirred at $0{ }^{\circ} \mathrm{C}$ for about $0.5 \mathrm{~h}$. A solution of $\mathbf{1}(0.86 \mathrm{~g}, 3.5 \mathrm{mmol})$ or $\mathbf{2}(0.83 \mathrm{~g}, 3.5 \mathrm{mmol})$ in $10 \mathrm{~mL}$ of DMF was then added in one portion. After the evolution of $\mathrm{H}_{2}$ had ceased, the suspension was stirred at room temperature for further $30 \mathrm{~min}$ and then heated under reflux for appropriate time $(\approx 6 \mathrm{~h}, \mathrm{TLC})$. After completion of the reaction, the produced mixture was cooled, poured into ice-water, and acidified with $\mathrm{HCl}\left(1 \mathrm{~mol} \mathrm{~L}^{-1}\right)$ to $\mathrm{pH} \approx 5$, followed by extraction with ethyl acetate $(3 \times 50 \mathrm{~mL})$. The combined organic phase was dried over anhydrous $\mathrm{Na}_{2} \mathrm{SO}_{4}$. After removal of the volatile material under vacuum, the resulting residue was chromatographed on silica gel with $n$-hexane/ $\mathrm{CHCl}_{3}(7: 3, V / V)$ to give the corresponding products 4a-h, followed by elution with $n$-hexane/ $\mathrm{CHCl}_{3}(1: 1, V / V)$ to give $3 \mathbf{a}-\mathbf{h}$.

When the above reactions (1/2 with the same phosphorus reagents) proceeded in $\mathrm{MeOH}$ solution containing sodium methanoate $(\mathrm{MeONa})$ and a catalytic amount of 2,3-dichloro-5,6-dicyanobenzoquinone (DDQ), thiadiazolo-phosphonates 4a-h were exclusively obtained in $75-80 \%$ yield.

Reaction of $\mathbf{1 / 2}$ with diethyl (methylthiomethyl)phosphonate and diethyl (methylthioethyl) phosphonate

Synthesis of $\mathbf{6} \boldsymbol{a}$ and $\boldsymbol{b}$. - According to the general procedure, a mixture of $\mathbf{1}(0.86 \mathrm{~g}, 3.5$ $\mathrm{mmol})$, diethyl (methylthiomethyl)phosphonate $(0.83 \mathrm{~g}, 4.2 \mathrm{mmol}$ ) or diethyl (methylthioethyl)phosphonate $(0.89 \mathrm{~g}, 4.2 \mathrm{mmol}), 0.1 \mathrm{~g}$ of sodium $(8.4 \mathrm{mmol})$, and a catalytic amount of DDQ in $20 \mathrm{~mL} \mathrm{MeOH}$ was stirred at room temperature for half an hour. The reaction mixture was further refluxed for $\approx 6 \mathrm{~h}$ (TLC) to give a material that was assigned thiadiazine2-phosphonate (6a).

The same procedure and addition of the same amounts to the reaction of 2 with diethyl (methylthiomethyl)phosphonate $(0.83 \mathrm{~g}, 4.2 \mathrm{mmol})$ or diethyl (methylthio-ethyl)phosphonate afforded the corresponding thiadiazine-2-phosphonate $6 \mathbf{b}$.

\section{Reaction of $\mathbf{1 / 2}$ with diethyl 2-methylallylphosphonate}

Synthesis of $8 \boldsymbol{a}, \boldsymbol{b}$. - Following the general procedure and using the same amounts, $\mathbf{1} / \mathbf{2}$ reacted with diethyl 2-methylallylphosphonate $(0.80 \mathrm{~g}, 4.2 \mathrm{mmol})$ in the presence of DDQ to give phosphonates $\mathbf{8 a}$ or $\mathbf{8 b}$ after heating under reflux for $8 \mathrm{~h}$.

Solvents of crystallization, yields, physical analytical data and spectral data (MS, IR, ${ }^{1} \mathrm{H}-,{ }^{13} \mathrm{C}-$, and $\left.{ }^{31} \mathrm{P}-\mathrm{NMR}\right)$ for the new products $\mathbf{3} \mathbf{a}-\mathbf{h}, \mathbf{4} \mathbf{a}-\mathbf{h}, \mathbf{6} \mathbf{\mathbf { a }}, \mathbf{b}$ and $\mathbf{8} \mathbf{a}, \mathbf{b}$ are collected in Tables I and II.

\section{Pharmacology}

Biological activity spectra prediction. - Biological activity spectra were predicted for substrates $\mathbf{1 / 2}$ and synthesized structures $\mathbf{3} \mathbf{a}-\mathbf{h}, \mathbf{4} \mathbf{a}-\mathbf{h}, \mathbf{6 a}, \mathbf{b}, \mathbf{8} \mathbf{a}$ and $\mathbf{b}$ with the molecular assisted program PASS 2009.1 version (IBMC, Moscow, Russia). The prediction result is pre- 
Table I. Physical and analytical data for compounds $3 a-h, 4 a-h, 6 a, b, 8 a$ and $\boldsymbol{b}$

\begin{tabular}{|c|c|c|c|c|c|c|c|c|}
\hline \multirow{2}{*}{ Product / appearance } & \multirow{2}{*}{$\begin{array}{c}\text { M.p. } \\
\left({ }^{\circ} \mathrm{C}\right) / \text { yield }(\%)\end{array}$} & \multirow{2}{*}{$\begin{array}{c}\text { Mol. form. }\left(M_{\mathrm{r}}\right) \\
\text { MS: } m / z(\%)=\left[\mathrm{M}^{+}\right]\end{array}$} & \multicolumn{6}{|c|}{ Calcd./found (\%) } \\
\hline & & & $\mathrm{C}$ & $\mathrm{H}$ & $\mathrm{Cl}$ & $\mathrm{N}$ & $\mathrm{P}$ & S \\
\hline $3 a$ & $186^{\mathrm{a}}$ & $\mathrm{C}_{17} \mathrm{H}_{27} \mathrm{~N}_{6} \mathrm{O}_{3} \mathrm{PS}_{2}(458.54)$ & 44.53 & 5.94 & - & 18.33 & 6.75 & 13.99 \\
\hline Colorless needles & $(54)$ & $458(<7)\left[\mathrm{M}^{+}\right]$ & 44.58 & 5.86 & - & 18.39 & 6.68 & 13.95 \\
\hline $3 b$ & $134^{\mathrm{b}}$ & $\mathrm{C}_{17} \mathrm{H}_{25} \mathrm{~N}_{6} \mathrm{O}_{3} \mathrm{PS}(424.46)$ & 48.10 & 5.94 & - & 19.80 & 7.30 & 7.55 \\
\hline Colorless crystals & (53) & $424(<5)\left[\mathrm{M}^{+}\right]$ & 48.17 & 5.88 & - & 19.75 & 7.33 & 7.59 \\
\hline $3 c$ & $168^{c}$ & $\mathrm{C}_{18} \mathrm{H}_{28} \mathrm{~N}_{5} \mathrm{O}_{5} \mathrm{PS}(457.48)$ & 47.26 & 6.17 & - & 15.31 & 6.77 & 7.01 \\
\hline Colorless solid & $(55)$ & $457(<6)\left[\mathrm{M}^{+}\right]$ & 47.33 & 6.11 & - & 15.28 & 6.81 & 6.93 \\
\hline $3 d$ & $156^{\mathrm{d}}$ & $\mathrm{C}_{19} \mathrm{H}_{30} \mathrm{~N}_{5} \mathrm{O}_{5} \mathrm{PS}(471.51)$ & 48.40 & 6.41 & - & 14.85 & 6.57 & 6.80 \\
\hline Colorless solid & (54) & $471(<7)\left[\mathrm{M}^{+}\right]$ & 48.33 & 6.35 & - & 14.78 & 6.65 & 6.84 \\
\hline $3 e$ & $172^{\mathrm{e}}$ & $\mathrm{C}_{15} \mathrm{H}_{21} \mathrm{ClN}_{5} \mathrm{O}_{3} \mathrm{PS}_{2}$ (449.92) & 40.04 & 4.70 & 7.88 & 15.57 & 6.88 & 14.25 \\
\hline Colorless crystals & (53) & $449(<4)\left[\mathrm{M}^{+}\right]$ & 40.09 & 4.63 & 7.83 & 15.49 & 6.92 & 14.31 \\
\hline $3 f$ & $128^{\mathrm{b}}$ & $\mathrm{C}_{15} \mathrm{H}_{19} \mathrm{ClN}_{5} \mathrm{O}_{3} \mathrm{PS}$ (415.83) & 43.33 & 4.61 & 8.53 & 16.84 & 7.45 & 7.71 \\
\hline Colorless solid & (56) & $415(<6)\left[\mathrm{M}^{+}\right]$ & 43.39 & 4.57 & 8.48 & 16.77 & 7.53 & 7.75 \\
\hline $3 g$ & $167^{\mathrm{f}}$ & $\mathrm{C}_{16} \mathrm{H}_{22} \mathrm{ClN}_{4} \mathrm{O}_{5} \mathrm{PS}(448.86)$ & 42.81 & 4.94 & 7.90 & 12.48 & 6.90 & 7.14 \\
\hline Colorless crystals & $(54)$ & $448(<5)\left[\mathrm{M}^{+}\right]$ & 42.86 & 4.87 & 7.85 & 12.44 & 6.93 & 7.20 \\
\hline $3 h$ & $152^{\mathrm{d}}$ & $\mathrm{C}_{17} \mathrm{H}_{24} \mathrm{ClN}_{4} \mathrm{O}_{5} \mathrm{PS}$ (462.89) & 44.11 & 5.23 & 7.66 & 12.10 & 6.69 & 6.93 \\
\hline Colorless needles & (55) & $462(<7)\left[\mathrm{M}^{+}\right]$ & 44.14 & 5.18 & 7.59 & 12.05 & 6.63 & 6.89 \\
\hline $4 a$ & $176^{\mathrm{f}}$ & $\mathrm{C}_{17} \mathrm{H}_{25} \mathrm{~N}_{6} \mathrm{O}_{3} \mathrm{PS}_{2}(456.52)$ & 44.73 & 5.52 & - & 18.41 & 6.78 & 14.05 \\
\hline Straw yellow needles & $(77)$ & $456(<7)\left[\mathrm{M}^{+}\right]$ & 44.81 & 5.46 & - & 18.37 & 6.87 & 14.11 \\
\hline $4 b$ & $128^{\mathrm{b}}$ & $\mathrm{C}_{17} \mathrm{H}_{23} \mathrm{~N}_{6} \mathrm{O}_{3} \mathrm{PS}(422.44)$ & 48.33 & 5.49 & - & 19.89 & 7.33 & 7.59 \\
\hline Pale yellow crystals & $(79)$ & $422(<5)\left[\mathrm{M}^{+}\right]$ & 48.40 & 5.41 & - & 19.83 & 7.38 & 7.54 \\
\hline $4 c$ & $156^{\mathrm{i}}$ & $\mathrm{C}_{18} \mathrm{H}_{26} \mathrm{~N}_{5} \mathrm{O}_{5} \mathrm{PS}(455.47)$ & 47.47 & 5.75 & - & 15.38 & 6.80 & 7.04 \\
\hline Straw yellow crystals & $(77)$ & $455(<7)\left[\mathrm{M}^{+}\right]$ & 47.52 & 5.68 & - & 15.34 & 6.86 & 7.09 \\
\hline $4 d$ & $146^{\mathrm{i}}$ & $\mathrm{C}_{19} \mathrm{H}_{28} \mathrm{~N}_{5} \mathrm{O}_{5} \mathrm{PS}(469.49)$ & 48.61 & 6.01 & - & 14.92 & 6.60 & 6.83 \\
\hline Straw yellow crystals & $(80)$ & $469(<6)\left[\mathrm{M}^{+}\right]$ & 48.67 & 5.96 & - & 14.85 & 6.54 & 6.88 \\
\hline $4 e$ & $164^{\mathrm{e}}$ & $\mathrm{C}_{15} \mathrm{H}_{19} \mathrm{ClN}_{5} \mathrm{O}_{3} \mathrm{PS}_{2}(447.90)$ & 40.22 & 4.28 & 7.92 & 15.64 & 6.92 & 14.32 \\
\hline Pale yellow needles & $(76)$ & $447(<5)\left[\mathrm{M}^{+}\right]$ & 40.28 & 4.21 & 7.87 & 15.55 & 6.88 & 14.37 \\
\hline $4 f$ & $120^{\mathrm{e}}$ & $\mathrm{C}_{15} \mathrm{H}_{17} \mathrm{ClN}_{5} \mathrm{O}_{3} \mathrm{PS}$ (413.82) & 43.54 & 4.14 & 8.57 & 16.92 & 7.48 & 7.75 \\
\hline Straw yellow crystals & $(78)$ & $413(<5)\left[\mathrm{M}^{+}\right]$ & 43.61 & 4.09 & 8.51 & 16.88 & 7.54 & 7.71 \\
\hline $4 g$ & $155^{\mathrm{d}}$ & $\mathrm{C}_{16} \mathrm{H}_{20} \mathrm{ClN}_{4} \mathrm{O}_{5} \mathrm{PS}(446.85)$ & 43.01 & 4.51 & 7.93 & 12.54 & 6.93 & 7.18 \\
\hline Pale yellow needles & $(80)$ & $446(<8)\left[\mathrm{M}^{+}\right]$ & 43.07 & 4.47 & 7.88 & 12.46 & 6.89 & 7.21 \\
\hline $4 h$ & $138^{\mathrm{b}}$ & $\mathrm{C}_{17} \mathrm{H}_{22} \mathrm{ClN}_{4} \mathrm{O}_{5} \mathrm{PS}(460.87)$ & 44.30 & 4.81 & 7.69 & 12.16 & 6.72 & 6.96 \\
\hline Straw yellow solid & (78) & $460(<5)\left[\mathrm{M}^{+}\right]$ & 44.35 & 4.77 & 7.63 & 12.12 & 6.64 & 6.89 \\
\hline
\end{tabular}


W. M. Abdou et al.: Design, synthesis and pharmacological screening of $\beta$-amino-, thiadiazole/thiadiazine-phosphonate based triazole motifs as antimicrobial/cytotoxic agents, Acta Pharm. 64 (2014) 267-284.

\begin{tabular}{ccccccccc} 
6a & $176^{\mathrm{a}}$ & $\mathrm{C}_{16} \mathrm{H}_{22} \mathrm{~N}_{5} \mathrm{O}_{3} \mathrm{PS}(395.4)$ & 48.60 & 5.61 & - & 17.71 & 7.83 & 8.11 \\
yellow crystals & $(71)$ & $395(<4)\left[\mathrm{M}^{+}\right]$ & 48.64 & 5.54 & - & 17.65 & 7.88 & 8.14 \\
6b & $162^{\mathrm{c}}$ & $\mathrm{C}_{14} \mathrm{H}_{16} \mathrm{ClN}_{4} \mathrm{O}_{3} \mathrm{PS}(386.79)$ & 43.47 & 4.17 & 9.17 & 14.48 & 8.01 & 8.29 \\
Straw yellow crystals & $(72)$ & $386(<6)\left[\mathrm{M}^{+}\right]$ & 43.42 & 4.11 & 9.14 & 14.44 & 8.09 & 8.33 \\
8a & $187^{\mathrm{i}}$ & $\mathrm{C}_{19} \mathrm{H}_{28} \mathrm{~N}_{5} \mathrm{O}_{3} \mathrm{PS}(437.50)$ & 52.16 & 6.45 & - & 16.01 & 7.08 & 7.33 \\
yellow needles & $(75)$ & $437(13)\left[\mathrm{M}^{+}\right]$ & 52.20 & 6.41 & - & 15.96 & 7.01 & 7.39 \\
8b & $172^{\mathrm{j}}$ & $\mathrm{C}_{17} \mathrm{H}_{22} \mathrm{ClN}_{4} \mathrm{O}_{3} \mathrm{PS}(428.87)$ & 47.61 & 5.17 & 8.27 & 13.06 & 7.22 & 7.48 \\
yellow needles & $(74)$ & $428(27)\left[\mathrm{M}^{+}\right]$ & 47.66 & 5.13 & 8.21 & 13.03 & 7.28 & 7.44 \\
\hline
\end{tabular}

Solvents for crystalization: ${ }^{\mathrm{a}} \mathrm{EtOH},{ }^{\mathrm{b}} \mathrm{cyclohexane},{ }^{\mathrm{c}} \mathrm{MeCN},{ }^{\mathrm{d}}$ acetone, ${ }^{\mathrm{e}} \mathrm{CH}_{2} \mathrm{Cl}_{2} / \mathrm{Me}_{2} \mathrm{O}(1: 1, V / V),{ }^{\mathrm{f}}$ ligroin, ${ }^{\mathrm{g}}$ pentane, hacetone, ${ }^{\mathrm{i}} \mathrm{CHCl}_{3},{ }^{\mathrm{j}} \mathrm{EtOH} / \mathrm{Me}_{2} \mathrm{O}(1: 1, V / V)$.

Table II. IR, ${ }^{1} \boldsymbol{H}-,{ }^{31} \mathrm{P}$ - and ${ }^{13} \mathrm{C}$ NMR spectral data for compounds $\mathbf{3} \boldsymbol{a}-\boldsymbol{h}, \mathbf{4} \boldsymbol{a}-\boldsymbol{h}, \mathbf{6} \boldsymbol{a}, \boldsymbol{b}, \mathbf{8} \boldsymbol{a}$ and $\boldsymbol{b}$

\begin{tabular}{|c|c|c|c|}
\hline \multicolumn{2}{|c|}{$\begin{array}{l}\text { Compd. IR } \\
\qquad\left(\mathrm{KBr}, v_{\max ^{\prime}} \mathrm{cm}^{-1}\right)\end{array}$} & ${ }^{1} \mathrm{H}$ and ${ }^{31} \mathrm{P}$ NMR $(\delta, \mathrm{ppm})$ & ${ }^{13} \mathrm{C}$ NMR $(\delta, \mathrm{ppm})$ \\
\hline $3 a$ & $\begin{array}{l}3408,3318(\mathrm{NH}, \\
\left.\mathrm{NH}_{2}\right), 2455(\mathrm{SH}), \\
1245(\mathrm{P}=\mathrm{O}, \\
\text { bonded }), 1066 \\
(\mathrm{P}-\mathrm{O}-\mathrm{C})\end{array}$ & $\begin{array}{l}1.18\left(\mathrm{dt},{ }^{3} J_{\mathrm{H}-\mathrm{H}}=6.7,{ }^{4} J_{\mathrm{P}-\mathrm{H}}=4.4 \mathrm{~Hz}, 6 \mathrm{H},\right. \\
2 \mathrm{MeCOP}), 2.82(\mathrm{br}, 1 \mathrm{H}, \mathrm{HS}), 2.94 \\
(\mathrm{~s}, 6 \mathrm{H}, \mathrm{NMe}), 3.24\left(\mathrm{dd},{ }^{3} J_{\mathrm{H}-\mathrm{H}}=15.7,\right. \\
\left.{ }^{2} J_{\mathrm{P}-\mathrm{H}}=20.6 \mathrm{~Hz}, 1 \mathrm{H}, \mathrm{H}^{a} \mathrm{C}-\mathrm{P}\right), 4.34(\mathrm{dq}, \\
\left.{ }^{3} J_{\mathrm{H}-\mathrm{H}}=6.7,{ }^{3} J_{\mathrm{P}-\mathrm{H}}=7.1 \mathrm{~Hz}, 4 \mathrm{H}, 2 \mathrm{H}_{2} \mathrm{CO}\right) \\
4.58\left(\mathrm{~m}, 1 \mathrm{H}, \mathrm{H}^{b} \mathrm{C}\right), 6.68,7.68(2 \mathrm{~d}, \\
\left.{ }^{3} \mathrm{H}_{\mathrm{H}-\mathrm{H}}=9.4 \mathrm{~Hz}, 4 \mathrm{H}, H-\mathrm{Ar}\right), 8.58(\mathrm{~s}, 1 \mathrm{H}, \\
H \mathrm{C}-\text { triazole }), 10.33\left(\mathrm{~d},{ }^{3} J_{\mathrm{H}-\mathrm{H}}=6.8 \mathrm{~Hz},\right. \\
1 \mathrm{H}, H \mathrm{~N}), 11.2\left(\mathrm{br}, 2 \mathrm{H}, \mathrm{H}_{2} \mathrm{~N}\right) ; \delta_{\mathrm{P}} 21.4\end{array}$ & 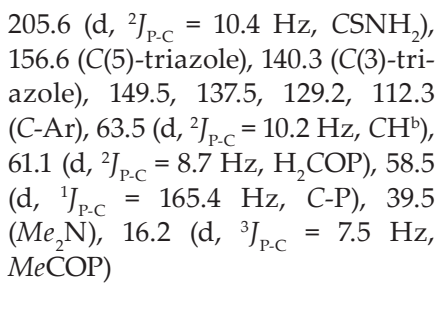 \\
\hline
\end{tabular}

3b $3348(\mathrm{NH}), 24101.34\left(\mathrm{dt},{ }^{3} J_{\mathrm{H}-\mathrm{H}}=6.5,{ }^{4} J_{\mathrm{P}-\mathrm{H}}=4.9 \mathrm{~Hz}, 6 \mathrm{H}, 157.1(C(5)\right.$-triazole), $140.8(C(3)$-tri(SH), $2233(\mathrm{CN}), \quad 2 \mathrm{MeCOP}), 2.64(\mathrm{br}, 1 \mathrm{H}, \mathrm{HS}), 2.99$ azole), 150.1, 134.5, 133.1, 112.6 $1233\left(\mathrm{P}=\mathrm{O}, \quad\left(\mathrm{s}, 6 \mathrm{H}, \mathrm{NMe} e_{2}\right), 3.26\left(\mathrm{dd},{ }^{3} J_{\mathrm{H}-\mathrm{H}}=17.4,(\mathrm{C}-\mathrm{Ar}), 111.3\left(\mathrm{~d},{ }^{2} J_{\mathrm{P}-\mathrm{C}}=8.5 \mathrm{~Hz}, \mathrm{CN}\right)\right.\right.$, bonded), $\left.1090 \quad{ }^{2} J_{\mathrm{P}-\mathrm{H}}=20.1 \mathrm{~Hz}, 1 \mathrm{H}, \mathrm{H}^{a} \mathrm{C}-\mathrm{P}\right), 4.22\left(\mathrm{dq}, 62.5\left(\mathrm{~d},{ }^{2} J_{\mathrm{P}-\mathrm{C}}=8.5 \mathrm{~Hz}, \mathrm{H}_{2} \mathrm{COP}\right), 60.5\right.$ (P-O-C) $\left.\quad{ }^{3} J_{\mathrm{H}-\mathrm{H}}=6.5,{ }^{3} J_{\mathrm{P}-\mathrm{H}}=6.8 \mathrm{~Hz}, 4 \mathrm{H}, 2 \mathrm{H}_{2} \mathrm{COP}\right), \quad\left(\mathrm{d},{ }^{2} J_{\mathrm{P}-\mathrm{C}}=11.3 \mathrm{~Hz}, \mathrm{CH}^{\mathrm{b}}\right), 40.2(\mathrm{NMe})$, $4.81\left(\mathrm{~m}, 1 \mathrm{H}, H^{b} \mathrm{C}\right), 6.64,7.64\left(2 \mathrm{~d}, 35.8\left(\mathrm{~d},{ }^{1} J_{\mathrm{P}-\mathrm{C}}=183.6 \mathrm{~Hz}, \mathrm{C}-\mathrm{P}\right), 16.5\right.$ $\left.{ }^{3} J_{\mathrm{H}-\mathrm{H}}=9.2 \mathrm{~Hz}, 4 \mathrm{H}, \mathrm{H}-\mathrm{Ar}\right), 8.27\left(\mathrm{~s}, 1 \mathrm{H}, \quad\left(\mathrm{d},{ }^{3} \mathrm{~J}_{\mathrm{P}-\mathrm{C}}=7.3 \mathrm{~Hz}, \mathrm{MeCOP}\right)\right.$

HC-triazole), $10.12\left(\mathrm{~d},{ }^{3} J_{\mathrm{H}-\mathrm{H}}=6.7 \mathrm{~Hz}\right.$,

$1 \mathrm{H}, H \mathrm{~N}) ; \delta_{\mathrm{P}} 24.2$

3c $3422(\mathrm{NH}), 23851.27\left(\mathrm{dt},{ }^{3} J_{\mathrm{H}-\mathrm{H}}=6.9,{ }^{4} J_{\mathrm{P}-\mathrm{H}}=4.8 \mathrm{~Hz}, 166.1\left(\mathrm{~d},{ }^{2} J_{\mathrm{P}-\mathrm{C}}=8.9 \mathrm{~Hz}, \mathrm{C}=\mathrm{O}\right), 157.7\right.$ (SH), $\left.1693(\mathrm{C}=\mathrm{O}), \quad 6 \mathrm{H}, 2 \mathrm{H}_{3} \mathrm{CCOP}\right), 2.38$ (br, 1H, HS), 3.07 (C(5)-triazole), 141.1 (C(3)-triazole), $1251\left(\mathrm{P}=\mathrm{O}, \quad(\mathrm{s}, 6 \mathrm{H}, \mathrm{NMe})_{2}\right), 3.25\left(\mathrm{dd},{ }^{3} J_{\mathrm{H}-\mathrm{H}}=13.9,147.5,135.9,134.7,112.1(\mathrm{C}-\mathrm{Ar}), 62.4\right.$ bonded), $\left.1050 \quad{ }^{2} J_{\mathrm{P}-\mathrm{H}}=19.8 \mathrm{~Hz}, 1 \mathrm{H}, \mathrm{H}^{a} \mathrm{C}-\mathrm{P}\right), 3.71\left(\mathrm{~s}, 3 \mathrm{H},\left(\mathrm{d},{ }^{2} J_{\mathrm{P}-\mathrm{C}}=9.1 \mathrm{~Hz}, \mathrm{H}_{2} \mathrm{COP}\right), 61.7(\mathrm{~d}\right.$, $(\mathrm{P}-\mathrm{O}-\mathrm{C}) \quad \mathrm{MeCO}), 4.15\left(\mathrm{dq},{ }^{3} J_{\mathrm{H}-\mathrm{H}}=6.9,{ }^{3} \mathrm{~J}_{\mathrm{P}-\mathrm{H}}=7.3 \quad{ }^{2} J_{\mathrm{P}-\mathrm{C}}=10.2 \mathrm{~Hz}, \mathrm{CH}^{\mathrm{b}}\right), 52.8\left(\mathrm{MeCO}_{2}\right)$, $\left.\mathrm{Hz}, 4 \mathrm{H}, 2 \mathrm{H}_{2} \mathrm{COP}\right), 5.16(\mathrm{~m}, 1 \mathrm{H}, \mathrm{CH}), 48.6\left(\mathrm{~d},{ }^{1} \mathrm{JP}_{\mathrm{P}-\mathrm{C}}=180.6 \mathrm{~Hz}, \mathrm{C}-\mathrm{P}\right), 40.5$ $6.62,7.45\left(2 \mathrm{~d},{ }^{3} J_{\mathrm{H}-\mathrm{H}}=8.7 \mathrm{~Hz}, 4 \mathrm{H},\left(\mathrm{NMe}_{2}\right), 16.7\left(\mathrm{~d},{ }^{3} J_{\mathrm{P}-\mathrm{C}}=6.9 \mathrm{~Hz}\right.\right.$, H-Ar), 8.07 (s, 1H, HC-triazole), $9.74 \mathrm{H}_{3} \mathrm{CCOP}$ )

$\left(\mathrm{d},{ }^{3} J_{\mathrm{H}-\mathrm{H}}=6.9 \mathrm{~Hz}, 1 \mathrm{H}, H \mathrm{~N}\right) ; \delta_{\mathrm{P}} 22.8$ 
$3 d \quad 3434(\mathrm{NH}), 2419 \quad 1.18-1.32\left(\mathrm{~m}, 9 \mathrm{H}, \mathrm{MeC} . \mathrm{CO}_{2} \& 2 \mathrm{MeCOP}\right), 166.3\left(\mathrm{~d},{ }^{2} \mathrm{P}_{\mathrm{P}-\mathrm{C}}=10.2 \mathrm{~Hz}, \mathrm{C}=\mathrm{O}\right), 156.9$ (SH), $1687(\mathrm{C}=\mathrm{O}), 2.40$ (br, 1H, HS), $3.13(\mathrm{~s}, 6 \mathrm{H}, \mathrm{NMe}$ ), (C(5)-triazole), $141.2(\mathrm{C}(3)$-triazole), $1255(\mathrm{P}=\mathrm{O}$, bonded), 1039 (P-O-C)

3 e $3395,3315(\mathrm{NH}$, $\left.\mathrm{NH}_{2}\right), 2480(\mathrm{SH})$, $1229(\mathrm{P}=\mathrm{O}$, bonded), 1042 (P-O-C) $1229(\mathrm{P}=\mathrm{O}), 1082$ (P-O-C)

$3 g \quad 3372(\mathrm{NH}), 2448$ (SH), $1706(\mathrm{C}=\mathrm{O})$, $1228(\mathrm{P}=\mathrm{O}$, bonded), 1058 (P-O-C)

3h $3431(\mathrm{NH}), 2356$ (SH), $1610(\mathrm{C}=\mathrm{O})$, $1233(\mathrm{P}=\mathrm{O}$, bonded), 1024 (P-O-C)

4a $\quad 3333-3320(\mathrm{NH}$, bonded), 1045 $(\mathrm{P}-\mathrm{O}-\mathrm{C})$ $3.32\left(\mathrm{dd},{ }^{3} J_{\mathrm{H}-\mathrm{H}}=14.3,{ }^{2} J_{\mathrm{P}-\mathrm{H}}=16.5 \mathrm{~Hz}, 147.3,135.9,134.6,112.6(\mathrm{C}-\mathrm{Ar}), 62.9\right.$ $\left.1 \mathrm{H}, \mathrm{H}^{a} \mathrm{C}-\mathrm{P}\right), 4.16-4.28\left(\mathrm{~m}, 6 \mathrm{H}, \mathrm{H}_{2} \mathrm{CCO}_{2}\left(\mathrm{~d},{ }^{2} J_{\mathrm{P}-\mathrm{C}}=9.7 \mathrm{~Hz}, \mathrm{H}_{2} \mathrm{CO}\right), 61.8(\mathrm{~d}\right.$, \& $\left.\left.2 \mathrm{H}_{2} \mathrm{COP}\right), 5.17\left(\mathrm{~m}, 1 \mathrm{H}, \mathrm{CH}^{b}\right), 6.68,{ }^{2} J_{\mathrm{P}-\mathrm{C}}=9.2 \mathrm{~Hz}, \mathrm{CH}^{\mathrm{b}}\right), 60.5\left(\mathrm{H}_{2} \mathrm{CCO}\right)$, $7.67\left(2 \mathrm{~d},{ }^{3} J_{\mathrm{H}-\mathrm{H}}=8.2 \mathrm{~Hz}, 4 \mathrm{H}, \mathrm{H}-\mathrm{Ar}\right), 8.5749 .2\left(\mathrm{~d},{ }^{1} J_{\mathrm{P}-\mathrm{C}}=180.6 \mathrm{~Hz}, \mathrm{C}-\mathrm{P}\right), 40.4$ (s, 1H, HC-triazole), $9.75\left(\mathrm{~d},{ }^{3} J_{\mathrm{H}-\mathrm{H}}=(\mathrm{NMe})_{2}\right), 16.9\left(\mathrm{~d},{ }^{3} J_{\mathrm{P}-\mathrm{C}}=6.8 \mathrm{~Hz}\right.$, $6.8 \mathrm{~Hz}, 1 \mathrm{H}, H \mathrm{~N}) ; \delta_{\mathrm{P}} 21.9$ $\mathrm{MeCOP}), 14.5(\mathrm{MeCCO})$

$1.29\left(\mathrm{dt},{ }^{3} J_{\mathrm{H}-\mathrm{H}}=8.3,{ }^{4} J_{\mathrm{P}-\mathrm{H}}=4.5 \mathrm{~Hz}, 6 \mathrm{H}, 205.9\left(\mathrm{~d},{ }^{2} J_{\mathrm{P}-\mathrm{C}}=10.2 \mathrm{~Hz}, \mathrm{C}=\mathrm{S}\right), 157.7\right.$ 2MeCOP), 2.42 (br, 1H, HS), 3.11 (dd, (C(5)-triazole), 141.3 (C(3)-triazole), $\left.{ }^{3} J_{\mathrm{H}-\mathrm{H}}=14.2,{ }^{2} J_{\mathrm{P}-\mathrm{H}}=19.3 \mathrm{~Hz}, 1 \mathrm{H}, \mathrm{H}^{a} \mathrm{C}-\mathrm{P}\right), 147.2,134.6,133.5,131.7$ (C-Ar), 63.5 $4.15\left(\mathrm{dq},{ }^{3} J_{\mathrm{H}-\mathrm{H}}=8.3,{ }^{3} J_{\mathrm{P}-\mathrm{H}}=6.5 \mathrm{~Hz}, 4 \mathrm{H}, \quad\left(\mathrm{d},{ }^{2} J_{\mathrm{P}-\mathrm{C}}=10.6 \mathrm{~Hz}, \mathrm{CH}^{\mathrm{b}}\right), 61.9(\mathrm{~d}\right.$, $\left.\left.2 \mathrm{H}_{2} \mathrm{COP}\right), 4.65\left(\mathrm{~m}, 1 \mathrm{H}, \mathrm{CH}^{b}\right), 6.99,7.93{ }^{2} J_{\mathrm{P}-\mathrm{C}}=9.7 \mathrm{~Hz}, \mathrm{H}_{2} \mathrm{COP}\right), 59.5\left(\mathrm{~d},{ }^{1} J_{\mathrm{P}-\mathrm{C}}=\right.$ $\left(2 \mathrm{~d},{ }^{3} J_{\mathrm{H}-\mathrm{H}}=9.3 \mathrm{~Hz}, 4 \mathrm{H}, \mathrm{H}-\mathrm{Ar}\right), 8.63(\mathrm{~s}, 178.4 \mathrm{~Hz}, \mathrm{C}-\mathrm{P}), 16.5\left(\mathrm{~d},{ }^{3} J_{\mathrm{P}-\mathrm{C}}=7.2 \mathrm{~Hz}\right.$, HC-triazole), $9.73\left(\mathrm{~d},{ }^{3} J_{\mathrm{H}-\mathrm{H}}=6.8 \mathrm{~Hz}, \mathrm{H}_{3} \mathrm{CCOP}\right)$

$1 \mathrm{H}, H \mathrm{~N}), 10.85\left(\mathrm{br}, 2 \mathrm{H}, H_{2} \mathrm{~N}\right) ; \delta_{\mathrm{P}} 24.7$

$1.16\left(\mathrm{dt},{ }^{3} J_{\mathrm{H}-\mathrm{H}}=6.4,{ }^{4} \mathrm{~J}_{\mathrm{P}-\mathrm{H}}=4.7 \mathrm{~Hz}, 6 \mathrm{H}, 156.9\right.$ (C(5)-triazole), 141.8 (C(3)-tri2MeCOP), 2.54 (br, 1H, HS), 3.31 (dd, azole), 143.5, 134.7, 133.6, 129.7 $\left.{ }^{3} J_{\mathrm{H}-\mathrm{H}}=10.4,{ }^{2} J_{\mathrm{P}-\mathrm{H}}=23.5 \mathrm{~Hz}, 1 \mathrm{H}, \mathrm{H}^{a} \mathrm{C}-\mathrm{P}\right), \quad(\mathrm{C}-\mathrm{Ar}), 111.4\left(\mathrm{~d},{ }^{2} J_{\mathrm{P}-\mathrm{C}}=11.5 \mathrm{~Hz}, \mathrm{CN}\right)$, $4.18\left(\mathrm{dq},{ }^{3} J_{\mathrm{H}-\mathrm{H}}=6.4,{ }^{3} J_{\mathrm{P}-\mathrm{H}}=7.1 \mathrm{~Hz}, 4 \mathrm{H}, 62.3\left(\mathrm{~d},{ }^{2} J_{\mathrm{P}-\mathrm{C}}=8.7 \mathrm{~Hz}, \mathrm{H}_{2} \mathrm{COP}\right)\right.$, $\left.2 \mathrm{H}_{2} \mathrm{COP}\right), 5.02\left(\mathrm{~m}, 1 \mathrm{H}, \mathrm{CH}^{b}\right), 7.45,7.8760 .7\left(\mathrm{~d},{ }^{2} J_{\mathrm{P}-\mathrm{C}}=12.1 \mathrm{~Hz}, \mathrm{CH}^{\mathrm{b}}\right), 36.3(\mathrm{~d}$, $\left.\left(2 \mathrm{~d},{ }^{3} J_{\mathrm{H}-\mathrm{H}}=9.4 \mathrm{~Hz}, 4 \mathrm{H}, \mathrm{H}-\mathrm{Ar}\right), 8.39{ }^{1} \mathrm{~J}_{\mathrm{P}-\mathrm{C}}=183.6 \mathrm{~Hz}, \mathrm{C}-\mathrm{P}\right), 16.4\left(\mathrm{~d},{ }^{3} J_{\mathrm{P}-\mathrm{C}}=\right.$ (s, 1H, HC-triazole), $10.08\left(\mathrm{~d},{ }^{3} J_{\mathrm{H}-\mathrm{H}}=7.5 \mathrm{~Hz}, \mathrm{MeCOP}\right)$

$6.8 \mathrm{~Hz}, 1 \mathrm{H}, H \mathrm{~N}) ; \delta_{\mathrm{P}} 23.6$

$1.21\left(\mathrm{dt},{ }^{3} J_{\mathrm{H}-\mathrm{H}}=6.3,{ }^{4} \mathrm{~J}_{\mathrm{P}-\mathrm{H}}=4.5,6 \mathrm{H}, 166.5\left(\mathrm{~d},{ }^{2} J_{\mathrm{P}-\mathrm{C}}=10.3 \mathrm{~Hz}, \mathrm{CO}\right), 157.5\right.$ $2 \mathrm{MeCOP}), 2.66$ (br, 1H, HS), 3.66 (dd, (C(5)-triazole), 141.3 (C(3)-triazole), $\left.{ }^{3} J_{\mathrm{H}-\mathrm{H}}=13.9,{ }^{2} J_{\mathrm{P}-\mathrm{H}}=19.8 \mathrm{~Hz}, 1 \mathrm{H}, \mathrm{H}^{a} \mathrm{C}-\mathrm{P}\right), 144.6,133.2,131.7,129.5$ (C-Ar), $3.82(\mathrm{~s}, 3 \mathrm{H}, \mathrm{MeC}), 4.25\left(\mathrm{dq},{ }^{3} J_{\mathrm{H}-\mathrm{H}}=6.3,61.9\left(\mathrm{~d},{ }^{2} J_{\mathrm{P}-\mathrm{C}}=14.6 \mathrm{~Hz}, \mathrm{CH}^{\mathrm{b}}\right), 61.1(\mathrm{~d}\right.$, $\left.{ }^{3} J_{\mathrm{P}-\mathrm{H}}=8.3 \mathrm{~Hz}, 4 \mathrm{H}, 2 \mathrm{H}_{2} \mathrm{CO}\right), 5.23\left(\mathrm{~m},{ }^{2} J_{\mathrm{P}-\mathrm{C}}=9.8 \mathrm{~Hz}, \mathrm{H}_{2} \mathrm{COP}\right), 52.6\left(\mathrm{MeCO}_{2}\right)$, $\left.1 \mathrm{H}, \mathrm{CH}^{b}\right), 7.31,7.68\left(2 \mathrm{~d},{ }^{3} J_{\mathrm{H}-\mathrm{H}}=8.7 \mathrm{~Hz}, 47.6\left(\mathrm{~d},{ }^{1} J_{\mathrm{P}-\mathrm{C}}=169.6 \mathrm{~Hz}, \mathrm{C}-\mathrm{P}\right), 16.5\right.$ $4 \mathrm{H}, \mathrm{H}$-Ar), 8.57 (s, 1H, HC-triazole), $\left(\mathrm{d},{ }^{3} \mathrm{~J}_{\mathrm{P}-\mathrm{C}}=7.9 \mathrm{~Hz}, \mathrm{MeCOP}\right)$ $9.64\left(\mathrm{~d},{ }^{3} J_{\mathrm{H}-\mathrm{H}}=7.8 \mathrm{~Hz}, 1 \mathrm{H}, H \mathrm{~N}\right) ; \delta_{\mathrm{P}} 22.6$

1.23-1.34 (m, 9H, MeC.CO \& $167.2\left(\mathrm{~d},{ }^{2} J_{\mathrm{P}-\mathrm{C}}=11.3 \mathrm{~Hz}, \mathrm{C}=\mathrm{O}\right), 156.7$, 2MeCOP), 2.63 (br, 1H, HS), 3.48 (dd, 141.4 (C(5)-, C(3)-triazole), 144.7, $\left.{ }^{3} J_{\mathrm{H}-\mathrm{H}}=12.1,{ }^{2} J_{\mathrm{P}-\mathrm{H}}=22.3 \mathrm{~Hz}, 1 \mathrm{H}, \mathrm{H}^{a} \mathrm{C}-\mathrm{P}\right), 135.5,132.7,130.6(\mathrm{C}-\mathrm{Ar}), 62.8(\mathrm{~d}$, 4.15-4.23 (m, 6H, $\left.\left.\mathrm{H}_{2} \mathrm{CCO}_{2} \& 2 \mathrm{H}_{2} \mathrm{COP}\right),{ }^{2} J_{\mathrm{P}-\mathrm{C}}=10.7 \mathrm{~Hz}, \mathrm{H}_{2} \mathrm{COP}\right), 62.4(\mathrm{~d}$, $5.34\left(\mathrm{~m}, 1 \mathrm{H}, \mathrm{CH}^{b}\right), 7.24,7.73\left(2 \mathrm{~d},{ }^{3} J_{\mathrm{H}-\mathrm{H}}={ }^{2} J_{\mathrm{P}-\mathrm{C}}=9.8 \mathrm{~Hz}, \mathrm{CH}_{\mathrm{b}}\right), 61.5\left(\mathrm{H}_{2} \mathrm{CCO}_{2}\right)$, $8.2 \mathrm{~Hz}, 4 \mathrm{H}, \mathrm{H}$-Ar), 8.65 (s, $1 \mathrm{H}, 49.2\left(\mathrm{~d},{ }^{1} J_{\mathrm{P}-\mathrm{C}}=180.6 \mathrm{~Hz}, \mathrm{C}-\mathrm{P}\right), 16.3$ (d, HC-triazole), $10.46\left(\mathrm{~d},{ }^{3} J_{\mathrm{H}-\mathrm{H}}=6.9 \mathrm{~Hz},{ }^{3} J_{\mathrm{P}-\mathrm{C}}=6.2 \mathrm{~Hz}, \mathrm{MeCOP}\right), 14.2$ $1 \mathrm{H}, \mathrm{HN}) ; \delta_{\mathrm{P}} 23.1$ $(\mathrm{MeCCO})$

$1.22\left(\mathrm{dt},{ }^{3} J_{\mathrm{H}-\mathrm{H}}=6.7,{ }^{4} J_{\mathrm{P}-\mathrm{H}}=4.3 \mathrm{~Hz}, 6 \mathrm{H}, 207.6\left(\mathrm{~d},{ }^{2} J_{\mathrm{P}-\mathrm{C}}=12.5 \mathrm{~Hz}, \mathrm{C}=\mathrm{S}\right), 159.2\right.$ $2 \mathrm{MeC}), 2.91(\mathrm{~s}, 6 \mathrm{H}, \mathrm{NMe}), 3.22$ (d, (C(5)-triazole), $141.5(\mathrm{C}(3)$-triazole), $\left.{ }^{2} J_{\mathrm{P}-\mathrm{H}}=18.8 \mathrm{~Hz}, 1 \mathrm{H}, \mathrm{HC}-\mathrm{P}\right), 4.02(\mathrm{dq}, 148.5,137.1,132.7,118.5$ (C-Ar), 77.5 $\left.{ }^{3} J_{\mathrm{H}-\mathrm{H}}=6.7,{ }^{3} J_{\mathrm{P}-\mathrm{H}}=6.4 \mathrm{~Hz}, 4 \mathrm{H}, 2 \mathrm{H}_{2} \mathrm{COP}\right), \quad\left(\mathrm{d},{ }^{2} J_{\mathrm{P}-\mathrm{C}}=12.9 \mathrm{~Hz}, \mathrm{C}-\mathrm{NH}\right), 62.7(\mathrm{~d}$, 6.59, $7.65\left(2 \mathrm{~d},{ }^{3} J_{\mathrm{H}-\mathrm{H}}=6.4 \mathrm{~Hz}, 4 \mathrm{H},{ }^{2} J_{\mathrm{P}-\mathrm{C}}=8.7 \mathrm{~Hz}, \mathrm{H}_{2} \mathrm{COP}\right), 58.7\left(\mathrm{~d},{ }^{1} J_{\mathrm{P}-\mathrm{C}}=\right.$ H-Ar), 8.58 (s, 1H, H(3)-triazole), 9.43, $\left.172.4 \mathrm{~Hz}, \mathrm{C}-\mathrm{P}), 39.1(\mathrm{NMe})_{2}\right), 15.7$ (d, $10.11\left(2 \mathrm{br}, 3 \mathrm{H}, \mathrm{NH}, \mathrm{NH}_{2}\right) ; \delta_{\mathrm{P}} 26.9$ 
4b $3341(\mathrm{NH}), 22161.23\left(\mathrm{dt},{ }^{3} J_{\mathrm{H}-\mathrm{H}}=6.1,{ }^{4} J_{\mathrm{P}-\mathrm{H}}=3.9 \mathrm{~Hz}, 6 \mathrm{H}, 156.3(\mathrm{C}(5)\right.$-triazole), $140.2(\mathrm{C}(3)$, $(\mathrm{CN}), 1234(\mathrm{P}=\mathrm{O}, \quad 2 \mathrm{MeCOP}), 2.99\left(\mathrm{~s}, 6 \mathrm{H}, \mathrm{Me} e_{2} \mathrm{~N}\right), 3.26(\mathrm{~d}$, triazole $), 148.5,133.5,131.9,118.3$ bonded), $\left.1075 \quad{ }^{2} J_{\mathrm{P}-\mathrm{H}}=20.5 \mathrm{~Hz}, 1 \mathrm{H}, \mathrm{HC}-\mathrm{P}\right), 4.22\left(\mathrm{dq},(\mathrm{C}-\mathrm{Ar}), 117.6\left(\mathrm{~d},{ }^{2} J_{\mathrm{P}-\mathrm{C}}=9.5 \mathrm{~Hz}, \mathrm{CN}\right)\right.$, (P-O-C) $\left.\quad{ }^{3} J_{\mathrm{H}-\mathrm{H}}=6.1,{ }^{3} J_{\mathrm{P}-\mathrm{H}}=5.7 \mathrm{~Hz}, 4 \mathrm{H}, 2 \mathrm{H}_{2} \mathrm{COP}\right), 78.3\left(\mathrm{~d},{ }^{2} \mathrm{~J}_{\mathrm{P}-\mathrm{C}}=11.9 \mathrm{~Hz}, \mathrm{C}-\mathrm{NH}\right), 61.3$ 6.64, $7.71\left(2 \mathrm{~d},{ }^{3} J_{\mathrm{H}-\mathrm{H}}=9.4 \mathrm{~Hz}, 4 \mathrm{H},\left(\mathrm{d},{ }^{2} J_{\mathrm{P}-\mathrm{C}}=7.9 \mathrm{~Hz}, \mathrm{H}_{2} \mathrm{COP}\right), 41.5\right.$ H-Ar), $8.57\left(\mathrm{~s}, 1 \mathrm{H}, \mathrm{H}(3)\right.$-triazole), $9.73\left(\mathrm{~N}\left(\mathrm{CH}_{3}\right)_{2}\right), 58.7\left(\mathrm{~d},{ }^{1} J_{\mathrm{P}-\mathrm{C}}=184.6 \mathrm{~Hz}\right.$, (br, $1 \mathrm{H}, H \mathrm{~N}) ; \delta_{\mathrm{p}} 27.6$ C-P), $15.6\left(\mathrm{~d},{ }^{3} J_{\mathrm{P}-\mathrm{C}}=6.8 \mathrm{~Hz}, \mathrm{MeCOP}\right)$

4c $\quad 3316(\mathrm{NH}), 1701 \quad 1.19\left(\mathrm{dt},{ }^{3} J_{\mathrm{H}-\mathrm{H}}=6.6,{ }^{4} J_{\mathrm{P}-\mathrm{H}}=4.5 \mathrm{~Hz}, 6 \mathrm{H}, 163.1\left(\mathrm{~d},{ }^{2} J_{\mathrm{P}-\mathrm{C}}=11.8 \mathrm{~Hz}, \mathrm{C}=\mathrm{O}\right), 155.7\right.$ $(\mathrm{C}=\mathrm{O}), 1238(\mathrm{P}=\mathrm{O}, 2 \mathrm{MeCOP}), 2.98\left(\mathrm{~s}, 6 \mathrm{H}, \mathrm{Me}{ }_{2} \mathrm{~N}\right), 3.32(\mathrm{~d},(\mathrm{C}(5)$-triazole), $141.6(\mathrm{C}(3)$-triazole), bonded), $\left.1093 \quad{ }^{2} J_{\mathrm{P}-\mathrm{H}}=16.8 \mathrm{~Hz}, 1 \mathrm{H}, \mathrm{HC}-\mathrm{P}\right), 3.76(\mathrm{~s}, 3 \mathrm{H}, 147.3,135.2,133.7,116.1(\mathrm{C}-\mathrm{Ar}), 82.7$ (P-O-C) $\quad \mathrm{MeCO}), 4.22\left(\mathrm{dq}^{3}{ }^{3} \mathrm{H}_{\mathrm{H}-\mathrm{H}}=6.6,{ }^{3} \mathrm{~J}_{\mathrm{P}-\mathrm{H}}=\left(\mathrm{d},{ }^{2} \mathrm{~J}_{\mathrm{P}-\mathrm{C}}=12.4 \mathrm{~Hz}, \mathrm{C}-\mathrm{NH}\right), 62.8(\mathrm{~d}\right.$, $\left.5.8 \mathrm{~Hz}, 4 \mathrm{H}, 2 \mathrm{H}_{2} \mathrm{COP}\right), 6.65,7.53\left(2 \mathrm{~d},{ }^{2} J_{\mathrm{P}-\mathrm{C}}=9.1 \mathrm{~Hz}, \mathrm{H}_{2} \mathrm{COP}\right), 52.9\left(\mathrm{MeCO}_{2}\right)$, $\left.{ }^{3} J_{\mathrm{H}-\mathrm{H}}=8.2 \mathrm{~Hz}, 4 \mathrm{H}, \mathrm{H}-\mathrm{Ar}\right), 8.07\left(\mathrm{~s}, 1 \mathrm{H}, 49.6\left(\mathrm{~d},{ }^{1} J_{\mathrm{P}-\mathrm{C}}=186.1 \mathrm{~Hz}, \mathrm{C}-\mathrm{P}\right)\right.$, HC-triazole), 9.54 (br, 1H, NH); $\left.\delta_{\mathrm{P}} 40.9(\mathrm{NMe})_{2}\right), 16.9\left(\mathrm{~d},{ }^{3} J_{\mathrm{P}-\mathrm{C}}=7.3 \mathrm{~Hz}\right.$, 24.7

$\mathrm{Me} \mathrm{COP})$

4d $3320(\mathrm{NH}), 1698 \quad 1.02-1.18\left(\mathrm{~m}, 9 \mathrm{H}, \mathrm{MeC} . \mathrm{CO}_{2^{\prime}} 2 \mathrm{MeCOP}\right), 165.4(\mathrm{C}(5)$-triazole $), 164.1\left(\mathrm{~d},{ }^{2} J_{\mathrm{P}-\mathrm{C}}=\right.$ $(\mathrm{C}=\mathrm{O}), 1242\left(\mathrm{P}=\mathrm{O}, 2.97\left(\mathrm{~s}, 6 \mathrm{H}, \mathrm{NM} e_{2}\right), 3.25\left(\mathrm{~d},{ }^{2} J_{\mathrm{P}-\mathrm{H}}=8.8 \mathrm{~Hz}, \mathrm{C}=\mathrm{O}\right), 142.4(\mathrm{C}(3)\right.$-triazole $)$, bonded), $1067 \quad 19.5 \mathrm{~Hz}, 1 \mathrm{H}, \mathrm{HC}-\mathrm{P}), 4.16-4.23(\mathrm{~m}, 6 \mathrm{H}, 148.3,134.8132 .9,118.6$ (C-Ar), 81.9 (P-O-C) $\left.\mathrm{H}_{2} \mathrm{CCO}_{2} \& 2 \mathrm{H}_{2} \mathrm{COP}\right), 6.58,7.67\left(2 \mathrm{~d},\left(\mathrm{~d},{ }^{2} J_{\mathrm{P}-\mathrm{C}}=12.7 \mathrm{~Hz}, \mathrm{C}-\mathrm{NH}\right), 62.5\right.$ $\left.{ }^{3} J_{\mathrm{H}-\mathrm{H}}=8.2 \mathrm{~Hz}, 4 \mathrm{H}, \mathrm{H}-\mathrm{Ar}\right), 8.54\left(\mathrm{~s}, 1 \mathrm{H}, \quad\left(\mathrm{d},{ }^{2} J_{\mathrm{P}-\mathrm{C}}=9.7 \mathrm{~Hz}, \mathrm{H}_{2} \mathrm{COP}\right), 61.8\right.$ HC-triazole), $9.35(\mathrm{br}, 1 \mathrm{H}, H \mathrm{~N}) ; \delta_{\mathrm{P}}\left(\mathrm{H}_{2} \mathrm{CCO}_{2}\right), 50.3\left(\mathrm{~d},{ }^{1} J_{\mathrm{P}-\mathrm{C}}=196.2 \mathrm{~Hz}\right.$, 28.4 $\mathrm{C}-\mathrm{P}), 41.3(\mathrm{NMe}), 16.3\left(\mathrm{~d},{ }^{3} \mathrm{P}_{\mathrm{P}-\mathrm{C}}=\right.$ $7.8 \mathrm{~Hz}, \mathrm{MeCOP}), 14.7\left(\mathrm{MeC} . \mathrm{CO}_{2}\right)$

$4 \mathrm{e} \quad 3330-3318\left(\mathrm{NH}, \quad 1.20\left(\mathrm{dt},{ }^{3} J_{\mathrm{H}-\mathrm{H}}=7.2,{ }^{4} J_{\mathrm{P}-\mathrm{H}}=4.3 \mathrm{~Hz}, 6 \mathrm{H}, 211.6\left(\mathrm{~d},{ }^{2} J_{\mathrm{P}-\mathrm{C}}=11.8 \mathrm{~Hz}, \mathrm{C}=\mathrm{S}\right), 160.2\right.\right.$ $\left.\mathrm{NH}_{2}\right), 1249(\mathrm{P}=\mathrm{O}, 2 \mathrm{MeCOP}), 3.21\left(\mathrm{~d},{ }^{2} J_{\mathrm{P}-\mathrm{H}}=20.8 \mathrm{~Hz}, 1 \mathrm{H}, \quad(\mathrm{C}(5)\right.$-triazole $), 141.3(\mathrm{C}(3)$-triazole $)$, bonded), 1048 $(\mathrm{P}-\mathrm{O}-\mathrm{C})$ HC-P), $4.23\left(\mathrm{dq},{ }^{3} J_{\mathrm{H}-\mathrm{H}}=7.2 \mathrm{~Hz},{ }^{3} J_{\mathrm{P}-\mathrm{H}}=145.5,135.7,133.9,132.2(\mathrm{C}-\mathrm{Ar}), 76.5\right.$ $\left.6.2 \mathrm{~Hz}, 4 \mathrm{H}, 2 \mathrm{CH}_{2} \mathrm{OP}\right), 7.24,8.25\left(2 \mathrm{~d},\left(\mathrm{~d},{ }^{2} \mathrm{~J}_{\mathrm{P}-\mathrm{C}}=11.7 \mathrm{~Hz}, \mathrm{C}-\mathrm{NH}\right), 61.3(\mathrm{~d}\right.$, $\left.{ }^{3} J_{\mathrm{H}-\mathrm{H}}=9.4 \mathrm{~Hz}, 4 \mathrm{H}, \mathrm{H}-\mathrm{Ar}\right), 8.48\left(\mathrm{~s}, 1 \mathrm{H},{ }^{2} J_{\mathrm{P}-\mathrm{C}}=9.6 \mathrm{~Hz}, \mathrm{H}_{2} \mathrm{COP}\right), 59.3\left(\mathrm{~d},{ }^{1} J_{\mathrm{P}-\mathrm{C}}=\right.$ HC-triazole), 9.23, $9.93(2 \mathrm{br}, 3 \mathrm{H}, \mathrm{HN}, 168.6 \mathrm{~Hz}, \mathrm{C}-\mathrm{P}), 16.7\left(\mathrm{~d},{ }^{3} \mathrm{~J}_{\mathrm{P}-\mathrm{C}}=6.8 \mathrm{~Hz}\right.$, $\left.\mathrm{H}_{2} \mathrm{~N}\right) ; \delta_{\mathrm{P}} 28.4$ $\mathrm{Me} \mathrm{COP})$

4f $3338(\mathrm{NH}), 22081.19\left(\mathrm{dt}^{3} \mathrm{~J}_{\mathrm{H}-\mathrm{H}}=6.9,{ }^{4} J_{\mathrm{P}-\mathrm{H}}=4.8 \mathrm{~Hz}, 6 \mathrm{H}, 157.9(C(5)\right.$-triazole), $140.8(C(3)$-tri$(\mathrm{CN}), 1235(\mathrm{P}=\mathrm{O}, \quad 2 \mathrm{MeCOP}), 3.06\left(\mathrm{~d},{ }^{2} J_{\mathrm{P}-\mathrm{H}}=26.3 \mathrm{~Hz}, 1 \mathrm{H}\right.$, azole $), 142.6,136.2,133.4,131.3$ bonded), $1110 \quad H C-\mathrm{P}), 4.26\left(\mathrm{dq},{ }^{3} J_{\mathrm{H}-\mathrm{H}}=6.9,{ }^{3} J_{\mathrm{P}-\mathrm{H}}=(\mathrm{C}-\mathrm{Ar}), 116.8\left(\mathrm{~d},{ }^{2} J_{\mathrm{P}-\mathrm{C}}=12.5 \mathrm{~Hz}, \mathrm{CN}\right)\right.$, (P-O-C) $\left.\quad 6.8 \mathrm{~Hz}, 4 \mathrm{H}, 2 \mathrm{H}_{2} \mathrm{COP}\right), 7.32,8.16\left(2 \mathrm{~d}, 77.8\left(\mathrm{~d},{ }^{2} J_{\mathrm{P}-\mathrm{C}}=12.7 \mathrm{~Hz}, \mathrm{C}-\mathrm{NH}\right), 62.7\right.$ $\left.{ }^{3} J_{\mathrm{H}-\mathrm{H}}=9.4 \mathrm{~Hz}, 4 \mathrm{H}, \mathrm{H}-\mathrm{Ar}\right), 8.63\left(\mathrm{~s}, 1 \mathrm{H}, \quad\left(\mathrm{d},{ }^{2} \mathrm{~J}_{\mathrm{P}-\mathrm{C}}=10.9 \mathrm{~Hz}, \mathrm{H}_{2} \mathrm{CO}\right), 42.9(\mathrm{~d}\right.$, HC-triazole), 9.54 (br, $\left.1 \mathrm{H}, H \mathrm{~N}) ; \delta_{\mathrm{P}}{ }^{1} J_{\mathrm{P}-\mathrm{C}}=178.6 \mathrm{~Hz}, \mathrm{C}-\mathrm{P}\right), 17.3\left(\mathrm{~d},{ }^{3} J_{\mathrm{P}-\mathrm{C}}=\right.$ $26.4 \quad 7.3 \mathrm{~Hz}, \mathrm{MeCOP})$

$4 \mathrm{~g} 3310(\mathrm{NH}), 16791.21\left(\mathrm{dt},{ }^{3} J_{\mathrm{H}-\mathrm{H}}=6.6,{ }^{4} J_{\mathrm{P}-\mathrm{H}}=4.8 \mathrm{~Hz}, 6 \mathrm{H}, 164.2\left(\mathrm{~d},{ }^{2} \mathrm{~J}_{\mathrm{P}-\mathrm{C}}=8.7 \mathrm{~Hz}, \mathrm{C}=\mathrm{O}\right), 156.4\right.$ $(\mathrm{C}=\mathrm{O}), 1252(\mathrm{P}=\mathrm{O}, 2 \mathrm{MeCOP}), 3.28\left(\mathrm{~d},{ }^{2} J_{\mathrm{P}-\mathrm{H}}=19.8 \mathrm{~Hz}, 1 \mathrm{H}, \quad(\mathrm{C}(5)\right.$-triazole $), 141.3(\mathrm{C}(3)$-triazole $)$, bonded), $1123 \quad H C-\mathrm{P}), 3.71(\mathrm{~s}, 3 \mathrm{H}, \mathrm{MeCO}), 4.22(\mathrm{dq}, 143.6,134.5,133.9,133.2(\mathrm{C}-\mathrm{Ar}), 82.3$ (P-O-C) $\left.{ }^{3} J_{\mathrm{H}-\mathrm{H}}=6.6,{ }^{3} J_{\mathrm{P}-\mathrm{H}}=6.3 \mathrm{~Hz}, 4 \mathrm{H}, 2 \mathrm{H}_{2} \mathrm{COP}\right), \quad\left(\mathrm{d},{ }^{2} J_{\mathrm{P}-\mathrm{C}}=12.7 \mathrm{~Hz}, \mathrm{C}-\mathrm{NH}\right), 62.3(\mathrm{~d}$, $7.26,8.13\left(2 \mathrm{~d},{ }^{3} J_{\mathrm{H}-\mathrm{H}}=8.7 \mathrm{~Hz}, 4 \mathrm{H},{ }^{2} J_{\mathrm{P}-\mathrm{C}}=13.6 \mathrm{~Hz}, \mathrm{H}_{2} \mathrm{COP}\right), \quad 52.4$ $\mathrm{H}$-Ar), 8.57 (s, 1H, HC-triazole), $9.62\left(\mathrm{MeCO}_{2}\right), 51.3\left(\mathrm{~d},{ }^{1} J_{\mathrm{P}-\mathrm{C}}=159.8 \mathrm{~Hz}\right.$, (br, $1 \mathrm{H}, H \mathrm{~N}) ; \delta_{\mathrm{P}} 26.9$

C-P), $16.4\left(\mathrm{~d},{ }^{3} J_{\mathrm{P}-\mathrm{C}}=7.8 \mathrm{~Hz}, \mathrm{MeCOP}\right)$ 
4h $3327(\mathrm{NH}), 1708 \quad 1.22-1.30 \quad\left(\mathrm{~m}, \quad 9 \mathrm{H}, \quad \mathrm{MeC} \cdot \mathrm{CO}_{2} \quad \& \quad 165.4\left(\mathrm{~d},{ }^{2} J_{\mathrm{P}-\mathrm{C}}=11.3 \mathrm{~Hz}, \mathrm{C}=\mathrm{O}\right), 155.9\right.$ $(\mathrm{C}=\mathrm{O}), 1227(\mathrm{P}=\mathrm{O}, 2 \mathrm{MeCOP}), 3.26\left(\mathrm{~d},{ }^{2} J_{\mathrm{P}-\mathrm{H}}=22.3 \mathrm{~Hz}, 1 \mathrm{H},(C(5)\right.$-triazole $), 141.7(C(3)$-triazole), bonded), $1133 \quad$ HC-P), 4.17-4.24 (m, 6H, $\mathrm{H}_{2} \mathrm{CCO}_{2} \& \quad$ 144.2, 135.1, 134.7, 133.8 (C-Ar), 82.7 (P-O-C) $\left.2 \mathrm{H}_{2} \mathrm{COP}\right), 7.32,8.24\left(2 \mathrm{~d},{ }^{3} \mathrm{H}_{\mathrm{H}-\mathrm{H}}=8.2 \mathrm{~Hz}, \quad\left(\mathrm{~d},{ }^{2} J_{\mathrm{P}-\mathrm{C}}=13.5 \mathrm{~Hz}, \mathrm{C}-\mathrm{NH}\right), 62.8(\mathrm{~d}\right.$, $4 \mathrm{H}, \mathrm{H}$-Ar), 8.65 (s, 1H, HC-triazole), $\left.{ }^{2} J_{\mathrm{P}-\mathrm{C}}=10.7 \mathrm{~Hz}, \mathrm{H}_{2} \mathrm{COP}\right), 61.5$ $9.46(\mathrm{br}, 1 \mathrm{H}, H \mathrm{~N}) ; \delta_{\mathrm{P}} 26.2$

$\left(\mathrm{H}_{2} \mathrm{CC}-\right), 49.8\left(\mathrm{~d},{ }^{1} J_{\mathrm{P}-\mathrm{C}}=188.6 \mathrm{~Hz}\right.$, $\mathrm{C}-\mathrm{P}), 16.7\left(\mathrm{~d},{ }^{3} J_{\mathrm{P}-\mathrm{C}}=6.2 \mathrm{~Hz}, \mathrm{MeCOP}\right)$, 14.2 (Me, ester)

6a $3415(\mathrm{NH}), 12621.25\left(\mathrm{dt},{ }^{3} J_{\mathrm{H}-\mathrm{H}}=6.6,{ }^{4} \mathrm{~J}_{\mathrm{P}-\mathrm{H}}=4.9 \mathrm{~Hz}, 6 \mathrm{H}, 155.8\left(\mathrm{~d},{ }^{2} J_{\mathrm{P}-\mathrm{C}}=12.3 \mathrm{~Hz}, \mathrm{C}-\mathrm{NH}\right)\right.$, $(\mathrm{P}=\mathrm{O}), 1115 \quad 2 \mathrm{MeCOP}), 3.05\left(\mathrm{~s}, 6 \mathrm{H}, \mathrm{Me}_{2} \mathrm{~N}\right), 4.12146 .3(\mathrm{C}(5)$-triazole $), 136.4\left(\mathrm{~d},{ }^{3} \mathrm{~J}_{\mathrm{P}-\mathrm{C}}=\right.$ $(\mathrm{P}-\mathrm{O}-\mathrm{C}) \quad\left(\mathrm{dq},{ }^{3} J_{\mathrm{H}-\mathrm{H}}=6.6,{ }^{3} J_{\mathrm{P}-\mathrm{H}}=6.4 \mathrm{~Hz}, 4 \mathrm{H}, 6.2 \mathrm{~Hz}, \mathrm{C}(3)\right.$-triazole $), 148.4,130.5$, $\left.2 \mathrm{H}_{2} \mathrm{COP}\right), 6.62,7.44\left(2 \mathrm{~d},{ }^{3} J_{\mathrm{H}-\mathrm{H}}=9.4 \mathrm{~Hz}, 124.3,114.7(\mathrm{C}-\mathrm{Ar}), 110.9\left(\mathrm{~d},{ }^{1} \mathrm{~J}_{\mathrm{P}-\mathrm{C}}=\right.\right.$ $4 \mathrm{H}, \mathrm{H}-\mathrm{Ar}), 8.25$ (s, 1H, HC-triazole), $148.6 \mathrm{~Hz}, \mathrm{C}-\mathrm{P}), 60.7\left(\mathrm{~d},{ }^{2} J_{\mathrm{P}-\mathrm{C}}=\right.$ $9.71(\mathrm{~s}, 1 \mathrm{H}, H \mathrm{~N}) ; \delta_{\mathrm{P}} 29.4$ $\left.10.9 \mathrm{~Hz}, \mathrm{H}_{2} \mathrm{COP}\right), 40.5(\mathrm{NMe}), 14.6$ $\left(\mathrm{d},{ }^{3} J_{\mathrm{P}-\mathrm{C}}=6.8 \mathrm{~Hz}, \mathrm{MeCOP}\right)$

6b $3433(\mathrm{NH}), 12641.33\left(\mathrm{dt},{ }^{3} J_{\mathrm{H}-\mathrm{H}}=6.6,{ }^{4} J_{\mathrm{P}-\mathrm{H}}=4.8 \mathrm{~Hz}, 6 \mathrm{H}, 155.4\left(\mathrm{~d},{ }^{2} J_{\mathrm{P}-\mathrm{C}}=12.9 \mathrm{~Hz}, \mathrm{C}-\mathrm{NH}\right)\right.$, $(\mathrm{P}=\mathrm{O}), 10852 \mathrm{MeCOP}), 4.22\left(\mathrm{dq},{ }^{3} J_{\mathrm{H}-\mathrm{H}}=6.6,{ }^{3} J_{\mathrm{P}-\mathrm{H}}=146.9(\mathrm{C}(5)\right.$-triazole $), 135.4\left(\mathrm{~d},{ }^{3} J_{\mathrm{P}-\mathrm{C}}=\right.$ (P-O-C) $\left.\quad 6.8 \mathrm{~Hz}, 4 \mathrm{H}, 2 \mathrm{H}_{2} \mathrm{COP}\right), 6.92,7.84(2 \mathrm{~d}, 5.9 \mathrm{~Hz}, \mathrm{C}(3)$-triazole), 136.4, 133.2, $\left.{ }^{3} J_{\mathrm{H}-\mathrm{H}}=8.9,4 \mathrm{H}, \mathrm{H}-\mathrm{Ar}\right), 8.31\left(\mathrm{~s}, 1 \mathrm{H}, 131.1,129.3(\mathrm{C}-\mathrm{Ar}), 109.8\left(\mathrm{~d},{ }^{1} J_{\mathrm{P}-\mathrm{C}}=\right.\right.$ $H C$-triazole), $\left.9.76(\mathrm{~s}, 1 \mathrm{H}, H \mathrm{~N}) ; \delta_{\mathrm{P}} 28.6128 .2 \mathrm{~Hz}, \mathrm{C}-\mathrm{P}\right), 61.2\left(\mathrm{~d},{ }^{2} J_{\mathrm{P}-\mathrm{C}}=\right.$ $\left.14.7 \mathrm{~Hz}, \mathrm{H}_{2} \mathrm{C}\right), 14.1\left(\mathrm{~d},{ }^{3} \mathrm{P}_{\mathrm{P}-\mathrm{C}}=7.3 \mathrm{~Hz}\right.$

8a $1256(\mathrm{P}=\mathrm{O}), 10751.07,1.12\left(2 \mathrm{~d},{ }^{3} J_{\mathrm{H}-\mathrm{H}}=6.5 \mathrm{~Hz}, 6 \mathrm{H}, 163.6\left(\mathrm{~d},{ }^{2} J_{\mathrm{P}-\mathrm{C}}=18.6 \mathrm{~Hz}, \mathrm{C}=\mathrm{N}\right), 147.3\right.$ (P-O-C) HC-Me $), 1.29\left(\mathrm{dt},{ }^{3} J_{\mathrm{H}-\mathrm{H}}=7.1,{ }^{4} J_{\mathrm{P}-\mathrm{H}}=(\mathrm{C}(3)\right.$-triazole $), 141.7\left(\mathrm{~d},{ }^{3} J_{\mathrm{P}-\mathrm{C}}=\right.$ $4.3 \mathrm{~Hz}, 6 \mathrm{H}, 2 \mathrm{MeCOP}$ ), 3.33 (d.sept, $6.4 \mathrm{~Hz}, \mathrm{C}(5)$-triazole), 149.3, 137.6, $\left.\left.{ }^{3} J_{\mathrm{H}-\mathrm{H}}=6.5,{ }^{3} J_{\mathrm{P}-\mathrm{H}}=6.4 \mathrm{~Hz}, 1 \mathrm{H}, \mathrm{HC}-\mathrm{Me}\right)_{2}\right), 134.6,116.7(\mathrm{C}-\mathrm{Ar}), 66.7\left(\mathrm{~d},{ }^{1} J_{\mathrm{P}-\mathrm{C}}=\right.$ $3.48(\mathrm{~s}, 6 \mathrm{H}, \mathrm{NMe}), 4.12\left(\mathrm{dq},{ }^{3} J_{\mathrm{H}-\mathrm{H}}=132.6 \mathrm{~Hz}, \mathrm{C}-\mathrm{P}\right), 62.2\left(\mathrm{~d},{ }^{2} J_{\mathrm{P}-\mathrm{C}}=\right.$ $\left.\left.7.1 \mathrm{~Hz},{ }^{3} J_{\mathrm{P}-\mathrm{H}}=7.5 \mathrm{~Hz}, 4 \mathrm{H}, 2 \mathrm{H}_{2} \mathrm{COP}\right), 12.4 \mathrm{~Hz}, \mathrm{H}_{2} \mathrm{COP}\right), 39.4\left(\mathrm{NMe}_{2}\right), 38.2$ $6.57,7.61\left(2 \mathrm{~d},{ }^{3} J_{\mathrm{H}-\mathrm{H}}=9.4 \mathrm{~Hz}, 4 \mathrm{H}, \mathrm{H}-\mathrm{Ar}\right), \quad\left(\mathrm{d},{ }^{2} J_{\mathrm{P}-\mathrm{C}}=12.4 \mathrm{~Hz}, \mathrm{HC}\left(\mathrm{CH}_{3}\right)_{2}\right), 22.8$ $8.33\left(\mathrm{~s}, 1 \mathrm{H}, H \mathrm{C}\right.$-triazole); $\left.\delta_{\mathrm{P}} 30.6 \quad\left(\mathrm{~d},{ }^{3} J_{\mathrm{P}-\mathrm{C}}=5.8 \mathrm{~Hz}, \mathrm{HCMe}\right)_{2}\right), 15.7(\mathrm{~d}$, $\left.{ }^{3} J_{\mathrm{P}-\mathrm{C}}=6.8 \mathrm{~Hz}, \mathrm{MeCOP}\right)$

8b $1265(\mathrm{P}=\mathrm{O}), 1065 \quad 0.98,1.11\left(2 \mathrm{~d},{ }^{3} J_{\mathrm{H}-\mathrm{H}}=6.9 \mathrm{~Hz}, 6 \mathrm{H}, 163.1\left(\mathrm{~d},{ }^{2} J_{\mathrm{P}-\mathrm{C}}=17.8 \mathrm{~Hz}, \mathrm{C}=\mathrm{N}\right), 147.7\right.$ $\left.(\mathrm{P}-\mathrm{O}-\mathrm{C}) \quad \mathrm{Me} e_{2}-\mathrm{CH}\right), 1.26\left(\mathrm{dt},{ }^{3} J_{\mathrm{H}-\mathrm{H}}=7.8,{ }^{4} J_{\mathrm{P}-\mathrm{H}}=(\mathrm{C}(3)\right.$-triazole $), 141.2\left(\mathrm{~d},{ }^{3} \mathrm{~J}_{\mathrm{P}-\mathrm{C}}=6.8 \mathrm{~Hz}\right.$, $4.6 \mathrm{~Hz}, 6 \mathrm{H}, 2 \mathrm{MeCOP}$ ), 3.38 (d. sept, $C(5)$-triazole), 140.5, 131.9, 130.2, $\left.{ }^{3} J_{\mathrm{H}-\mathrm{H}}=6.9,{ }^{3} J_{\mathrm{P}-\mathrm{H}}=6.8 \mathrm{~Hz}, 1 \mathrm{H}, \mathrm{HC}-\mathrm{Me} \mathrm{e}_{2}\right), 128.6(\mathrm{C}-\mathrm{Ar}), 67.2\left(\mathrm{~d},{ }^{1} \mathrm{~J}_{\mathrm{P}-\mathrm{C}}=144.5 \mathrm{~Hz}\right.$, $4.23\left(\mathrm{dq},{ }^{3} J_{\mathrm{H}-\mathrm{H}}=7.8,{ }^{3} J_{\mathrm{P}-\mathrm{H}}=6.7 \mathrm{~Hz}, 4 \mathrm{H}, \mathrm{C}-\mathrm{P}\right), 61.8\left(\mathrm{~d},{ }^{2} J_{\mathrm{P}-\mathrm{C}}=11.8 \mathrm{~Hz}, \mathrm{H}_{2} \mathrm{COP}\right)$, $\left.2 \mathrm{H}_{2} \mathrm{COP}\right), 7.41,8.02\left(2 \mathrm{~d},{ }^{3} J_{\mathrm{H}-\mathrm{H}}=8.6 \mathrm{~Hz}, 38.8\left(\mathrm{~d},{ }^{2} J_{\mathrm{P}-\mathrm{C}}=12.9 \mathrm{~Hz}, \mathrm{Me}_{2}-\mathrm{CH}\right)\right.$, $4 \mathrm{H}, \mathrm{H}-\mathrm{Ar}), 8.36$ (s, 1H, HC-triazole); $22.3\left(\mathrm{~d},{ }^{3} J_{\mathrm{P}-\mathrm{C}}=4.9 \mathrm{~Hz}, \mathrm{Me}_{2}-\mathrm{CH}\right), 16.9$ $\delta_{\mathrm{P}} 29.2$ $\left(\mathrm{d},{ }^{3} \mathrm{P}_{\mathrm{P}-\mathrm{C}}=5.7 \mathrm{~Hz}, \mathrm{MeCOP}\right)$

a Solvent for NMR: $\mathrm{CDCl}_{3}$.

b Solvent for NMR: DMSO- $d_{6}$.

sented as a list of activities in a table available as a supplementary document. The analysis of biological activity spectra prediction is an example of the in silico study of chemical compounds before experimental investigations. The biological activity spectrum for a substance is a list of biological activity types for which the probability to be revealed $(\mathrm{Pa})$ and the probability to be inactive $(\mathrm{Pi})$ are demonstrated. $\mathrm{Pa}$ and $\mathrm{Pi}$ values are independent and 
their values vary from 0 to 1 . PASS results showed that the antimicrobial and anticancer activities are the most common properties of the tested compounds.

Antimicrobial activity. - The antimicrobial activity of the synthesized phosphonates 3a-h, 4a-h, 6a,b, 8a and b was individually tested against a panel of Gram-positive and Gram-negative bacterial pathogens Klebseilla peunomoniae 2011E, Pseudomonas aeruginosa 6065 Y, Escherichia coli BW54, Escherichia coli BW55, Acinetobacter haemolyticus BW62, Steno-

Table III. Zone of growth inhibition ( $\mathrm{mm}$ ) of the new phosphor esters $\mathbf{3} \boldsymbol{a}-\boldsymbol{h}, \mathbf{4} \boldsymbol{a}-\boldsymbol{h}, \mathbf{6} \boldsymbol{a}, \boldsymbol{b}, \mathbf{8} \boldsymbol{a}$ and $\boldsymbol{b}$ against some bacteria

\begin{tabular}{|c|c|c|c|c|c|c|c|c|c|c|}
\hline \multirow[b]{2}{*}{ Compd. ${ }^{a}$} & \multicolumn{6}{|c|}{ Strain (Gram-negative) } & \multicolumn{4}{|c|}{ Strain (Gram-positive) } \\
\hline & 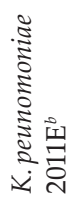 & 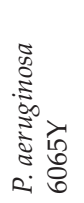 & 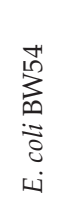 & 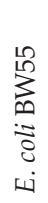 & 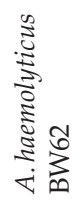 & 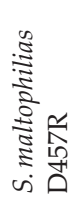 & 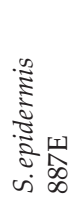 & 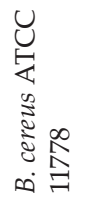 & 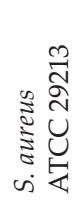 & 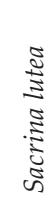 \\
\hline Cipro & 10 & 8 & 11 & 12 & 9 & 8 & 11 & 15 & 11 & 12 \\
\hline Chlor & 11 & 7 & 13 & 8 & 9 & 10 & 11 & 8 & 9 & 10 \\
\hline $3 a$ & 7 & 5 & 8 & 4 & 6 & 5 & 7 & 5 & $\leq 3^{\mathrm{b})}$ & 6 \\
\hline $3 b$ & $\leq 3$ & $\leq 3$ & $\leq 3$ & $\leq 3$ & $\leq 3$ & $\leq 3$ & $\leq 3$ & $\leq 3$ & $\leq 3$ & $\leq 3$ \\
\hline $3 c$ & 7 & 5 & 5 & 6 & 7 & 6 & 5 & $\leq 3$ & 5 & 6 \\
\hline $3 d$ & 7 & 6 & 4 & 7 & 8 & 4 & $\leq 3$ & 6 & 5 & 4 \\
\hline $3 e$ & 6 & 5 & 8 & 6 & $\leq 3$ & 5 & $\leq 3$ & 6 & 5 & 4 \\
\hline $3 f$ & $\leq 3$ & $\leq 3$ & $\leq 3$ & $\leq 3$ & $\leq 3$ & $\leq 3$ & $\leq 3$ & $\leq 3$ & $\leq 3$ & $\leq 3$ \\
\hline $3 g$ & 6 & 4 & $\leq 3$ & 6 & $\leq 3$ & 6 & 4 & 4 & 5 & 7 \\
\hline $3 h$ & 6 & 7 & 4 & 5 & 5 & 6 & 4 & $\leq 3$ & 6 & $\leq 3$ \\
\hline $4 a$ & 10 & 8 & 11 & 7 & 9 & 8 & 11 & 11 & 9 & 10 \\
\hline $4 b$ & $\leq 3$ & $\leq 3$ & $\leq 3$ & $\leq 3$ & $\leq 3$ & $\leq 3$ & $\leq 3$ & $\leq 3$ & $\leq 3$ & $\leq 3$ \\
\hline $4 c$ & 11 & 10 & 7 & 8 & 8 & 7 & 10 & 6 & 8 & 7 \\
\hline $4 d$ & 7 & 8 & 5 & 9 & 7 & 5 & 7 & 4 & 6 & 6 \\
\hline $4 e$ & 8 & 9 & 8 & 7 & 5 & 10 & 6 & 6 & 8 & 7 \\
\hline $4 \mathrm{f}$ & $\leq 3$ & $\leq 3$ & $\leq 3$ & $\leq 3$ & $\leq 3$ & $\leq 3$ & $\leq 3$ & $\leq 3$ & $\leq 3$ & $\leq 3$ \\
\hline $4 \mathrm{~g}$ & 9 & 8 & 6 & 7 & 9 & 8 & 7 & 11 & 7 & 8 \\
\hline $4 h$ & 6 & 7 & 5 & 6 & $\leq 3$ & 5 & 7 & 5 & 5 & $\leq 3$ \\
\hline $6 a$ & 8 & 6 & 5 & 7 & 5 & 4 & 6 & $\leq 3$ & 5 & 6 \\
\hline $6 b$ & 6 & 8 & 6 & 7 & 5 & 7 & 4 & 6 & 7 & 7 \\
\hline $8 a$ & 7 & 8 & 7 & 8 & 9 & $\leq 3$ & 6 & 5 & 5 & 6 \\
\hline $8 b$ & 4 & 6 & 5 & 6 & 4 & 4 & $\leq 3$ & 6 & 6 & 8 \\
\hline
\end{tabular}

${ }^{a}$ Concentration of each used compound is $10 \mu \mathrm{mol} \mathrm{L}-1$ (DMSO).

${ }^{\mathrm{b}}$ Compounds with $<3 \mathrm{~mm}$ growth inhibition zone were considered inactive. 
W. M. Abdou et al:: Design, synthesis and pharmacological screening of $\beta$-amino-, thiadiazole/thiadiazine-phosphonate based triazole motifs as antimicrobial/cytotoxic agents, Acta Pharm. 64 (2014) 267-284.

trophomonas maltophilia D457R, Staphylococcus epidermis 887E, Bacilllus cereus ATCC 11778, Staphylococcus aureus ATCC 29213 and Sacrina lutea. Ciprofloxacin (Cipro) and chloramphenicol (Chlor) were used as positive reference standards. Test compounds and drugs were used at a concentration of $10 \mu \mathrm{mol} \mathrm{mL}^{-1}$ (DMSO). Antimicrobial tests were carried out by the agar well diffusion method (21) using $100 \mathrm{~L}^{-1}$ of a suspension of the proper LB nutrient broth containing $1 \times 10^{8} \mathrm{CFU} \mathrm{mL} \mathrm{m}^{-1}$ bacteria. The antimicrobial activity was evaluated by measuring the zone of inhibition against the tested organisms and compared with that of the standards. Antimicrobial activities were expressed as the inhibition diameter zones in millimeters $(\mathrm{mm})$ and are presented in Table III. Each experiment was carried out in triplicate and the average zone of inhibition was calculated.

Minimal inhibitory (MIC) and minimal bactericidal concentration (MBC). - The bacteriostatic activity of the most active compounds $\mathbf{3 a}, \mathbf{e}, \mathbf{4 a}, \mathbf{c}, \mathbf{e}$ and $\mathbf{g}$ as well as the two reference drugs Cipro and Chlor was determined by the broth microdilution method on 96-well polystyrene flatbottom microtiter plates (Sarstedt, Germany), according to the Clinical Laboratory Standards Institute (CLSI) guidelines $(22,23)$. Antimicrobial activity was assessed for each compound in the concentration range from 450 to $10 \mu \mathrm{mol} \mathrm{L}^{-1}(450,200,100$, $50,25,10 \mu \mathrm{mol} \mathrm{L}^{-1}$ ) in cation-adjusted Mueller Hinton (MH) medium (Fluka, Switzerland). Overnight incubated cultures (at 30 or $37^{\circ} \mathrm{C}$ ) as appropriate in $\mathrm{MH}$, were standardized to $0.5 \mathrm{McF}$ arland units at $625 \mathrm{~nm}$. Each compound-containing well and the positive control wells were inoculated with $2 \times 108 \mathrm{CFU}$. Each plate included the positive control (bacteria without the antimicrobial) and the negative controls (medium only). The lowest concentration showing no growth was taken as the minimum inhibitory concentration (MIC). MIC was recorded as the lowest concentration of the compound that did not result in an absorbance at $595 \mathrm{~nm}$ that was higher than its respective control with compound after $24 \mathrm{~h}$ of incubation at $37^{\circ} \mathrm{C}$. Each assay was performed in triplicate. A strain is considered multiresistant when it is non-susceptible to at least 3 different classes of antimicrobial agents.

After $24 \mathrm{~h}$ of incubation, a spotting assay was performed in order to evaluate the minimum bacterial concentration $(M B C)$. Plates were prepared using LB nutrient broth solid medium, dried in a laminar flux chamber and inoculated with $5 \mathrm{~mL}$ of the content of each microplate pit. Plates were incubated at $37^{\circ} \mathrm{C}$ overnight for CFU counting. MBC was recorded as the lowest concentration that did not result in an eye-observable culture in solid medium after $24 \mathrm{~h}$ of incubation. Each assay was performed in triplicate.

Data of MIC / MBC are presented in Table IV.

Antitumor activity screening. - Antitumor potency of selected phosphonates $3 \mathbf{a}, \mathbf{c}, \mathbf{4 a}, \mathbf{c}, \mathbf{e}$, g, 6a and 8a in addition to substrate 1 was tested at a dose of $10 \mu \mathrm{mol} \mathrm{L}^{-1}$ (DMSO) utilizing 10 different human tumor cell lines. These lines represent breast [MCF7, MDA-MB-231/ ATCC, MDA-MB-435, BT-549), ovarian (IGROVI, OVCAR-3, SK-OV-3), prostate (PX-3, PU145), and liver (HEPG2) cells. Adriamycin (Adr) was used as a reference standard according to the reported methods $(24,25)$. Using absorbance measurements at $515 \mathrm{~nm}$ for each compound, for control growth and for test growth, the percent growth inhibition was calculated at each of the tested compound concentration level. Susceptibility testing assays were undertaken three times. Growth inhibition of $50 \%\left(G I_{50}\right)$ was calculated. Further studies on experimental tumors in vivo for evaluating the possible antineoplastic potential of the most promising compounds are in progress. 
W. M. Abdou et al.: Design, synthesis and pharmacological screening of $\beta$-amino-, thiadiazole/thiadiazine-phosphonate based triazole motifs as antimicrobial/cytotoxic agents, Acta Pharm. 64 (2014) 267-284.

Table IV. MIC and MBC of phosphonates $3 a, e, 4 a, c, e$ and $g$, Cipro and Chlor against bacteria

\begin{tabular}{|c|c|c|c|c|c|c|c|c|}
\hline Strain & $3 a$ & $3 e$ & $4 a$ & $4 c$ & $4 e$ & $4 g$ & Cipro & Chlor \\
\hline $\begin{array}{l}\text { K.peunomoniae } \\
2011 \mathrm{E}\end{array}$ & 279 / 436 & 173 / 555 & 70 / 70 & 96 / 439 & 71 / 141 & 67 / 143 & 97 / 97 & 55 / 99 \\
\hline $\begin{array}{l}\text { P. aeruginosa } \\
6065 \mathrm{Y}\end{array}$ & 120 / 279 & 173 / 555 & 70 / 70 & 96 / 439 & 143 / 223 & 142 / 142 & 96 / 96 & 99 / 99 \\
\hline $\begin{array}{l}\text { E. coli } \\
\text { BW54 }\end{array}$ & 120 / 279 & 66 / 222 & 65 / 140 & 66 / 141 & 22 / 44 & 142 / 448 & $96 / 96$ & 49 / 198 \\
\hline $\begin{array}{l}\text { E. coli } \\
\text { BW55 }\end{array}$ & 130 / 279 & 142 / 142 & 70 / 140 & 70 / 70 & 143 / 286 & 142 / 287 & 377 / 377 & $396 / 396$ \\
\hline $\begin{array}{l}\text { A.haemolyticus } \\
\text { BW62 }\end{array}$ & 70 / 218 & $284 / 284$ & $65 / 70$ & 154 / 439 & $56 / 71$ & 25 / 33 & 377 / 773 & 65 / 65 \\
\hline $\begin{array}{l}\text { S. maltophilia } \\
\text { D457R }\end{array}$ & 109 / 279 & 47 / 51 & 140 / 280 & 154 / 439 & 71 / 223 & 142 / 142 & 97 / 377 & $123 / 123$ \\
\hline $\begin{array}{l}\text { S. epidermis } \\
887 \mathrm{E}\end{array}$ & 109 / 279 & 153 / 555 & 70 / 140 & 75 / 219 & 71 / 223 & $18 / 22$ & 386 / 773 & 99 / 124 \\
\hline $\begin{array}{l}\text { B. cereus } \\
\text { ATCC } 11778\end{array}$ & 140 / 436 & 178 / 222 & 70 / 140 & 88 / 219 & 143 / 223 & 287 / 448 & 48 / 96 & 111 / 111 \\
\hline $\begin{array}{l}\text { S. aureus } \\
\text { ATCC } 29213\end{array}$ & $140 / 436$ & 178 / 222 & 54 / 121 & 88 / 141 & 71 / 223 & 287 / 448 & $96 / 96$ & 198 / 619 \\
\hline $\begin{array}{l}\text { Sacrina } \\
\text { lutea }\end{array}$ & 87 / 218 & 142 / 142 & $54 / 121$ & $121 / 219$ & 71 / 223 & 146 / 287 & 97 / 377 & 198 / 619 \\
\hline
\end{tabular}

MIC - minimum inhibitory concentration $\left(\mu \mathrm{mol} \mathrm{L} \mathrm{L}^{-1}\right), M B C$ - minimum bacterial concentration $\left(\mu \mathrm{mol} \mathrm{L}{ }^{-1}\right)$, Cipro ciprofloxacin, Chlor - chloramphenicol.

\section{RESULTS AND DISCUSSION}

\section{Chemistry}

Starting reaction sequences for the title compounds, $\beta$-amino- and fused thiadiazoloand thiadiazinephosphonates, are outlined in Schemes 1-3. Upon treatment with HornerWadsworth-Emmons (HWE) reagents (diethyl 2-amino-2-thioxoethyl-, cyanomethylphosphonate, methyl diethyl phosphonoacetate or triethyl phosphonoacetate), in DMF containing $\mathrm{LiH}, 1$,2,4-triazol-3-thiol substrates (1/2) yielded, after heating for appropriate time $(\approx 6 \mathrm{~h})$, the desired compounds $3 \mathbf{a}-\mathbf{h}$ and $4 \mathbf{a}-\mathbf{h}$. $\beta$-Amino-phosphonates $3 \mathbf{a}-\mathbf{h}(\approx 55 \%$ yield) were obtained via nucleophilic addition reaction that led to hydrophosphonylation of the imine function in $\mathbf{1 / 2}$. In the IR spectra of $\mathbf{3 a}-\mathbf{h}, \mathrm{NH}$ and $\mathrm{SH}$ bands were observed at about 3434-3315 and 2480-2356 cm $\mathrm{cm}^{-1}$. Appearance of $\mathrm{P}=\mathrm{O}$ (bonded) and $\mathrm{P}-\mathrm{O}-\mathrm{C}$ bands, re- 
spectively, at 1255-1228 and 1090-1024 $\mathrm{cm}^{-1}$ indicated the presence of a free SH group and confirmed preferred formation of an intramolecular hydrogen bond between the thiolproton and the phosphonate-oxygen atom. The configuration of $3\left(\delta_{\mathrm{p}} \approx 24.0 \mathrm{ppm}\right)$ was assigned as $E$-configuration, based on the ${ }^{1} \mathrm{H}$ NMR spectrum of, for example, 3 a that revealed four types of methine protons with different chemical shifts. The multiplet at $\delta 4.58 \mathrm{ppm}$ was assigned to $H^{b}$-proton, while the $\mathrm{P}-\mathrm{CH}^{\mathrm{a}}$ - proton resonated at $3.24\left(\mathrm{dd}, \mathrm{J}_{\mathrm{H}^{\mathrm{b}}-\mathrm{H}^{\mathrm{a}}}=15.7\right.$, ${ }^{2} J_{\mathrm{P}-\mathrm{H}}=20.6 \mathrm{~Hz}$ ) ppm. This large coupling constant $\left(J_{\mathrm{H}-\mathrm{H}}\right)$ of $\mathrm{H}^{b}$ with $\mathrm{H}^{a}$ as well as its coupling with phosphorus clearly indicates the anti-configuration of $H^{\mathrm{a}}$ to $H^{\mathrm{b}}-\mathrm{C}^{*}$. In addition, the thiol-proton was displayed at $2.82 \mathrm{ppm}$ (br) while the $\mathrm{NH}$ proton exhibited a doublet $\left(J_{\mathrm{H}-\mathrm{H}}=6.8 \mathrm{~Hz}\right)$ at $10.33 \mathrm{ppm}$, confirming the presence of $\mathrm{CH}^{\mathrm{b}}$ and $\mathrm{NH}$ in a $\mathrm{Z}$ rearrangement. The enantiospecific isomer 3 was also verified by careful inspection of a model in terms of the Newman projection (26), which confirmed the staggered anticonfiguration of $H^{b}$ and $H^{a}$. ${ }^{13} \mathrm{C}$ NMR spectrum of 3a revealed, among others, three doublets at $\delta_{\mathrm{C}} 205.6\left[\mathrm{~d},{ }^{2} J_{\mathrm{P}-\mathrm{C}}=10.4 \mathrm{~Hz}\right.$, $C(\mathrm{~S})], 63\left(\mathrm{~d},{ }^{2} J_{\mathrm{P}-\mathrm{C}}=10.2 \mathrm{~Hz}, \mathrm{CH}^{\mathrm{b}}-\mathrm{P}\right)$, and $\delta 58.5\left(\mathrm{~d},{ }^{1} J_{\mathrm{P}-\mathrm{C}}=165.4 \mathrm{~Hz}, \mathrm{C}-\mathrm{P}\right)$, whereas $\mathrm{Me}_{2} \mathrm{~N}$ moiety was displayed as a singlet at $\delta_{C} 39.5 \mathrm{ppm}$. The mass spectrum of 3a showed a peak corresponding to the molecular ion at $m / z(\%): 458(<7)\left[\mathrm{M}^{+}\right]$and $456(19)\left[\mathrm{M}^{+}-2\right]$ whereas the base peak was displayed at $215(100)\left[\mathrm{M}^{+}-243\left(2 \mathrm{H}+\mathrm{C}(\mathrm{S}) \mathrm{NH}_{2}+\mathrm{NMe}_{2}+\mathrm{PO}(\mathrm{OEt})_{2}\right)\right]$.

On the other hand, diethyl thiadiazole-5-methylenephosphonate (4a) was correctly identified as $\mathrm{C}_{17} \mathrm{H}_{25} \mathrm{~N}_{6} \mathrm{O}_{3} \mathrm{PS}_{2^{\prime}},\left\{\mathrm{m} / \mathrm{z}(\%): 455(19)\left[\mathrm{M}^{+}-1\right]\right.$ and the base peak at $214(100)\left[\mathrm{M}^{+}-242\right.$ $\left.\left.\left(\mathrm{H}+\mathrm{C}(\mathrm{S}) \mathrm{NH}_{2}+\mathrm{NMe}_{2}+\mathrm{PO}(\mathrm{OEt})_{2}\right)\right]\right\}$. The ${ }^{31} \mathrm{P} \mathrm{NMR}$ spectrum of $4 \mathbf{a}$, taken as an example, showed a positive signal at $\delta_{\mathrm{P}}=26.9 \mathrm{ppm}\left(v s . \mathrm{H}_{3} \mathrm{PO}_{4}\right)$, which indicates the phosphonate structure. In the NMR spectra of $4 \mathbf{a}$, the exocyclic methine moiety $(\mathrm{CH}-\mathrm{P})$ was found at $\delta_{\mathrm{H}}$ $3.22\left({ }^{2} J_{\mathrm{P}-\mathrm{H}}=18.8 \mathrm{~Hz}\right)$ and $\delta_{\mathrm{C}} 58.7 \mathrm{ppm}\left(\mathrm{d},{ }^{1} J_{\mathrm{P}-\mathrm{C}}=172.4 \mathrm{~Hz}\right)$. These data excluded any possible cyclization reaction involving the methylphosphonate moiety (structure 5, Scheme 1), and<smiles>Sc1nncn1/N=C/[Bi]</smiles>

$1 / 2$

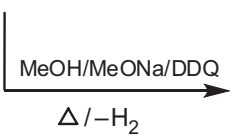

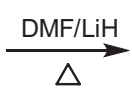<smiles>[R16][R]([H])([H])C([Y7])([2H])Nn1cnnc1SCOCC</smiles>

3a-h<smiles>[R]C([Pb]OCC)C1([Al])Sc2nncn2N1OCC</smiles><smiles>[R]C1(P(=O)([O-])CC)Sc2nncn2N=C1CO</smiles>

\begin{tabular}{c|c|c|c|c|c} 
3, 4 & $\mathrm{Ar}$ & $\mathrm{R}$ & $\mathbf{3 , 4}$ & $\mathrm{Ar}$ & \multicolumn{1}{c}{$\mathrm{R}$} \\
\hline $\mathbf{a}$ & $4-\mathrm{Me}_{2} \mathrm{~N}-\mathrm{Ph}$ & $\mathrm{C}(\mathrm{S}) \mathrm{NH}_{2}$ & $\mathbf{e}$ & $4-\mathrm{Cl}-\mathrm{Ph}$ & $\mathrm{C}(\mathrm{S}) \mathrm{NH}_{2}$ \\
b & $4-\mathrm{Me}_{2} \mathrm{~N}-\mathrm{Ph}$ & $\mathrm{CN}$ & $\mathbf{f}$ & $4-\mathrm{Cl}-\mathrm{Ph}$ & $\mathrm{CN}$ \\
$\mathbf{c}$ & $4-\mathrm{Me}_{2} \mathrm{~N}-\mathrm{Ph}$ & $\mathrm{CO}_{2} \mathrm{Me}$ & $\mathbf{g}$ & $4-\mathrm{Cl}-\mathrm{Ph}$ & $\mathrm{CO}_{2} \mathrm{Me}$ \\
d & $4-\mathrm{Me}_{2} \mathrm{~N}-\mathrm{Ph}$ & $\mathrm{CO}_{2} \mathrm{Et}$ & $\mathbf{h}$ & $4-\mathrm{Cl}-\mathrm{Ph}$ & $\mathrm{CO}_{2} \mathrm{Et}$
\end{tabular}

Scheme 1 
confirmed that the intramolecular cyclization proceeded via the other HC-Ar location. Furthermore, the ${ }^{1} \mathrm{H}$ NMR spectrum of 4 a showed other distinguished signals at $\delta 1.22(\mathrm{dt}$, $\left.{ }^{3} J_{\mathrm{H}-\mathrm{H}}=6.7,{ }^{4} J_{\mathrm{P}-\mathrm{H}}=4.3 \mathrm{~Hz}, 6 \mathrm{H}\right)$ and $4.02\left(\mathrm{dq},{ }^{3} J_{\mathrm{H}-\mathrm{H}}=6.7 \mathrm{~Hz},{ }^{3} J_{\mathrm{P}-\mathrm{H}}=6.4 \mathrm{~Hz}, 4 \mathrm{H}\right)$, which were assigned to the two ethoxyl groups attached to phosphorus [(EtO) $\mathrm{P}]$. In addition, the $\mathrm{N}$-dimethyl protons appeared as a singlet at $2.91(6 \mathrm{H})$, while the $\mathrm{NH}$ and $\mathrm{NH}_{2}$ protons appeared as broad signals at 9.43 and $10.11 \mathrm{ppm}$. The ${ }^{13} \mathrm{C}$ NMR spectrum of $4 \mathrm{a}$ showed the main signals at $207.6\left(\mathrm{~d},{ }^{2} J_{\mathrm{P}-\mathrm{C}}=12.5 \mathrm{~Hz}, \mathrm{C}=\mathrm{S}\right), 159.2$ [C(5)-triazole], 141.5 [C(3)-triazole], 148.5, 137.1, 132.7, 118.5 $(\mathrm{C}-\mathrm{Ar}), 77.5\left(\mathrm{~d},{ }^{2} J_{\mathrm{P}-\mathrm{C}}=12.9 \mathrm{~Hz}, \mathrm{C}-\mathrm{NH}\right), 62.7\left(\mathrm{~d},{ }^{2} J_{\mathrm{P}-\mathrm{C}}=8.7 \mathrm{~Hz}, \mathrm{H}_{2} \mathrm{COP}\right), 58.7\left(\mathrm{~d},{ }^{1} J_{\mathrm{P}-\mathrm{C}}=172.4 \mathrm{~Hz}\right.$, $\mathrm{C}-\mathrm{P}), 39.1\left(\mathrm{NMe}_{2}\right)$, and $15.7 \mathrm{ppm}\left(\mathrm{d},{ }^{3} J_{\mathrm{P}-\mathrm{C}}=6.9 \mathrm{~Hz}, \mathrm{H}_{3} \mathrm{CC}-\right)$.

Obviously, while the nucleophilic addition of methylene- $\mathrm{C}$ in phosphonate reagents gave rise to products $\mathbf{3 a - h}$, the slight homo-oxidation (air-oxidation) of $\mathbf{3}$ resulted in the formation of thiadiazoles 4 via intramolecular cyclization in tandem extrusion of a hydrogen molecule $(27,28)$. H-bond process was reported for the transformation of 3,5-di-tertbutyl-2-hydroxy phenylamino derivatives to the corresponding benzoxazoles $(14,26)$. Further, the air-oxidation process was previously discussed for the transformation of 4\{[(4-chlorophenyl)methylene]-amino\}-3-mercapto-methyl-3,4-dihydro-1,2,4-triazin$5(2 \mathrm{H})$-one to the respective fused pyrazoles (27). Thiadiazoles 4 were, however, exclusively obtained in 75-80\% yield when the above reactions [ $1 / 2$ and the same WHE reagents] proceeded in a methanol solution containing MeONa and a catalytic amount of 2,3-dichloro-5,6-dicyanobenzoquinone (DDQ) (29).

In contrast to the above results, reactions between $\mathbf{1 / 2}$ and diethyl [methyl(thioalkyl)] phosphonates proceeded only when a catalytic amount of DDQ was present in the medium (best yield, $\mathrm{MeOH} / \mathrm{MeONa} / \mathrm{DDQ}$ ) and yielded, in each case, the same product, thiadiazine-2-phosphonates $\mathbf{6 a}, \mathbf{b}(\approx 72 \%$ yield). As displayed in Scheme 2, compounds $\mathbf{6 a}, \mathbf{b}$ were formed via elimination of the alkylthiol motif from the initial intermediate $3 \mathbf{i}$, followed by intramolecular cyclization. Structure 6a showed strong absorption bands at $v_{\max } 3415(\mathrm{NH})$, $1262(\mathrm{P}=\mathrm{O})$, and at $1115(\mathrm{P}-\mathrm{O}-\mathrm{C})$ and disappearance of the band at $2420 \mathrm{~cm}^{-1}$ due to the $\mathrm{SH}$ group. The ${ }^{1} \mathrm{H}$ NMR $(\delta$, ppm) did not show a signal either due to the $\mathrm{SH}$ proton supposed to be around 2.8 while the $\mathrm{NH}$ proton appeared at 9.71. However, the two ethoxy $\left[\mathrm{P}(\mathrm{OEt})_{2}\right]$

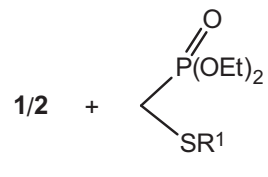

$\mathrm{R}^{1}=\mathrm{Me} ; \mathrm{Et}$
$\mathrm{MeONa} / \mathrm{MeOH} / \mathrm{DDQ}$
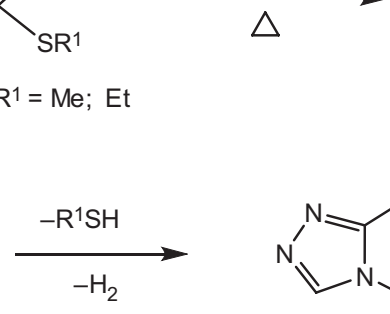

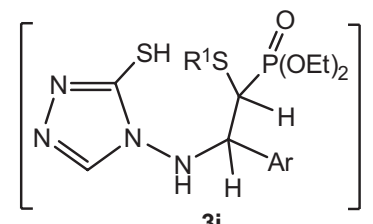

$3 \mathbf{i}$<smiles>CCO[PH](=O)C1=C([Al])Nn2cnnc2S1</smiles>

$6 a, b, A r$ as in $1 / 2$

Scheme 2 


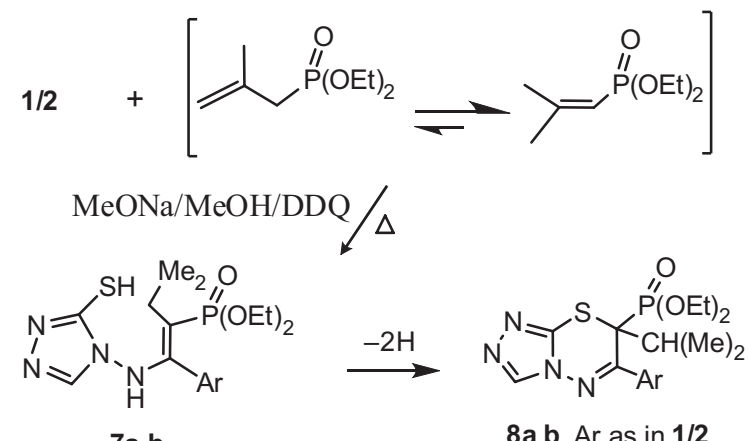

$7 a, b$

Scheme 3

protons were displayed at $1.25\left(\mathrm{dt}, J_{\mathrm{H}-\mathrm{H}}=6.6,{ }^{4} J_{\mathrm{P}-\mathrm{H}}=4.9 \mathrm{~Hz}, 6 \mathrm{H}, 2 \mathrm{MeCOP}\right)$, and $4.12(\mathrm{dq}$, $\left.J_{\mathrm{H}-\mathrm{H}}=6.6,{ }^{3} J_{\mathrm{P}-\mathrm{H}}=6.4 \mathrm{~Hz}, 4 \mathrm{H}, 2 \mathrm{H}_{2} \mathrm{COP}\right)$ while the $\mathrm{N}-\mathrm{Me}_{2}$ protons resonated as one singlet $(6 \mathrm{H})$ at 3.05. The ${ }^{13} \mathrm{C}$ NMR spectrum of 6 a showed, among others, $\mathrm{sp}^{3}-\mathrm{C}-(2)$ of the thiazine ring as a doublet $\left({ }^{1} J_{\mathrm{P}-\mathrm{C}}=148.6 \mathrm{~Hz}, \mathrm{C}-\mathrm{P}\right)$ at 110.9 , whereas $\mathrm{C}(3)$ (thiazine) appeared as a doublet $\left({ }^{3} J_{\mathrm{P}-\mathrm{C}}=6.2 \mathrm{~Hz}\right)$ at 136.4. The ${ }^{31} \mathrm{P}$ NMR shift of 6 a was recorded at $\delta_{\mathrm{P}} 29.4 \mathrm{ppm}$.

Finally, in a systematic study, 1,2,4-triazole-3-thiol-4-aminoarylidenes $\mathbf{1 / 2}$ were allowed to react with diethyl(2-methylallyl)phosphonate in $\mathrm{MeOH} / \mathrm{MeONa} / \mathrm{DDQ}$ solution to give the fused thiadiazine-5-methylphosphonates $8 \mathbf{a}, \mathbf{b}$ in $\approx 75 \%$ yield. According to the mechanism outlined in Scheme 3, Michael addition by imine 1/2 onto the isomerized ylide form of the phosphonate reagent resulted in the formation of final products $\mathbf{8} \mathbf{a}, \mathbf{b}$ via tandem loss of the $\mathrm{H}_{2}$ molecule from the initially formed intermediate 7 . The ${ }^{1} \mathrm{H}$ NMR spectrum $\left(\mathrm{CDCl}_{3}\right)$ of $8 \mathbf{a}\left(\delta_{\mathrm{P}} \approx 30 \mathrm{ppm}\right)$ showed, among others, a doublet of septet $\left({ }^{3} J_{\mathrm{H}-\mathrm{H}}=6.5\right.$, $\left.{ }^{3} J_{\mathrm{P}-\mathrm{H}}=6.4 \mathrm{~Hz}, 1 \mathrm{H}\right)$ at $\delta 3.33 \mathrm{ppm}$ due to the exocyclic methine-proton $\left(-\mathrm{CHMe}_{2}\right)$, two doublets $\left({ }^{3} J_{\mathrm{H}-\mathrm{H}}=6.5 \mathrm{~Hz}, 6 \mathrm{H}\right)$ at $\delta 1.07,1.12 \mathrm{ppm}$ due to the exocyclic methyl groups, a singlet at 3.48 ppm $(6 \mathrm{H})$ due to the $\mathrm{Me}_{2} \mathrm{~N}$ moiety. The ${ }^{13} \mathrm{C} \mathrm{NMR}\left(\mathrm{CDCl}_{3}\right)$ spectrum of 8a displayed the $-\mathrm{CHMe}_{2}$ moiety at $\delta 38.2 \mathrm{ppm}\left(\mathrm{d},{ }^{2} J_{\mathrm{P}-\mathrm{C}}=12.4 \mathrm{~Hz}\right)$ and at $\delta 22.8 \mathrm{ppm}\left({ }^{3} J_{\mathrm{P}-\mathrm{C}}=5.8 \mathrm{~Hz}\right)$, while $\mathrm{NMe}_{2}$ and C-P were, respectively, displayed at $\delta 39.4$ and $66.7 \mathrm{ppm}\left(\mathrm{d},{ }^{1} J_{\mathrm{P}-\mathrm{C}}=132.6 \mathrm{~Hz}\right)$.

\section{Pharmacology}

Antimicrobial evaluation. - Preliminary screening of new compounds $3 \mathbf{a}-\mathbf{h}, \mathbf{4} \mathbf{a}-\mathbf{h}, \mathbf{6} \mathbf{a}, \mathbf{b}$, $\mathbf{8} \mathbf{a}$ and $\mathbf{b}$ was evaluated in vitro against a panel of standard and clinically isolated strains of the Gram-negative and Gram-positive bacteria using the disc diffusion method and the results are presented in Table III. All tested phosphonates, except the compounds $\mathbf{3 b}, \mathbf{f}, \mathbf{4 b}$ and $\mathbf{f}$ (compounds that have a nitrile moiety), exhibited some antimicrobial activity. Measurement of the zone of growth inhibition for $10 \mu \mathrm{mol} \mathrm{mL} \mathrm{m}^{-1}(\mathrm{DMSO})$ of each compound showed that the most active compounds were the fused thiadiazole-phosphonates $4 \mathbf{a}, \mathbf{c}, \mathbf{e}$ and $\mathbf{g}$, which inhibited the growth of Gram-negative and Gram-positive bacteria. The most active compounds were selected for further screening. They all have in common the fusedthiadiazole ring, which suggests that the presence of this motif may be enhancing the activity. Even compounds $3 \mathbf{a}$ and $3 \mathbf{e}$, which were less active, were also selected. 
MIC and $M B C$ were then determined for the lead phosphonates $\mathbf{3 a}, \mathbf{e}, \mathbf{4} \mathbf{a}, \mathbf{c}, \mathbf{e}$ and $\mathbf{g}$, as well as two reference drugs ciprofloxacin and chloramphenicol. The activity was assessed for each drug in the range of concentrations from 450 to $10 \mu \mathrm{mol} \mathrm{L}^{-1}(450,200,100,50,25,10$ $\mu \mathrm{mol} \mathrm{L}{ }^{-1}$ ) in cation-adjusted Mueller Hinton medium (22) and the results are presented in Table IV.

The data displayed in Tables III and IV show that the two most active phosphonates were $4 \mathbf{a}$ and $4 \mathbf{e}$ with MIC of 54-140 and 22-143 $\mu \mathrm{mol} \mathrm{L}^{-1}$, whereas their MBC values were 70-439 and 44-268 $\mu \mathrm{mol} \mathrm{L}^{-1}$ against all the pathogens tested. For comparison, $M I C / M B C$ for ciprofloxacin were recorded at 48 to $386\left(M I C, \mu \mathrm{mol} \mathrm{L}^{-1}\right)$ and at 55 to 396 for $M B C \mu \mathrm{mol} \mathrm{L}-1$. On the other hand, $M I C / M B C$ for chloramphenicol were recorded at 70 to $439\left(M I C, \mu \mathrm{mol} \mathrm{L}^{-1}\right)$ and at 65 to 619 for $M B C \mu \mathrm{mol} \mathrm{L}-1$.

Antitumor activity. - Inspired by the optimized results of the prediction analysis, antitumor activity screening of $\mathbf{3 a}, \mathbf{c}, \mathbf{4} \mathbf{a}, \mathbf{c}, \mathbf{e}, \mathbf{g}, \mathbf{6} \mathbf{a}$ and $\mathbf{8} \mathbf{a}$ was tested applying carcinoma cell lines against adriamycin as a reference standard at a dose of $10 \mu \mathrm{mol} \mathrm{L}^{-1}$ (DMSO). Substrate 1 was also tested at the same dose in a trial to reflect the effect of introducing phosphonate derivatives. The results are displayed in Table $\mathrm{V}$ and show an interesting activity for several compounds. With the exception of substrate 1, all synthesized compounds reflected remarkable antitumor activity against breast (especially MDA-MB-231/ATCC and BT-549) and prostate carcinoma cell lines (PC-3 and DU-145), whereas a moderate to good effect was observed on ovarian and liver cancer cells. The order of activity for the tested compounds is: $3 a>3 c>4 a>4 e>4 c>4 g>6 a>8 a$. Structure-activity relationship correlation for these compounds revealed that the presence of dialkylamino or 4-chloro as a substitu-

Table V. Growth inhibition $\left(\mathrm{GI}_{50}\right)$ of $A d r, \mathbf{1}, 3 a, c, 4 a, c, 6 a$ and $8 a$ in vitro human tumor cell lines

\begin{tabular}{|c|c|c|c|c|c|c|c|c|c|c|}
\hline \multirow{2}{*}{ Panel/Cell line } & \multicolumn{10}{|c|}{$G_{50}\left(\mu \mathrm{mol} \mathrm{L}^{-1}\right)$ for compounds } \\
\hline & Adr & 1 & $3 \mathbf{a}$ & $3 c$ & $4 a$ & $4 c$ & $4 e$ & $4 \mathrm{~g}$ & $6 a$ & $8 a$ \\
\hline \multicolumn{11}{|l|}{ Breast cancer } \\
\hline MCF7 & 17.6 & $>202^{\mathrm{a}}$ & 19.2 & 27.5 & 31.5 & 41.3 & 49.8 & 38.5 & 67.5 & 59.7 \\
\hline MDA-MB-231/ATCC & 26.4 & $>202$ & 23.9 & 14.4 & 27.2 & 30.7 & 41.3 & 11.3 & 60.9 & 12.1 \\
\hline MDA-MB-435 & 26.9 & $>202$ & 16.1 & 22.5 & 36.4 & 33.8 & 33.2 & 56.8 & 81.7 & 32.9 \\
\hline BT-549 & 16.6 & $>202$ & 22.9 & 31.7 & 37.9 & 41.3 & 25.9 & 24.2 & 40.5 & 40.2 \\
\hline \multicolumn{11}{|l|}{ Ovarian cancer } \\
\hline IGROVI & 38.4 & $>202$ & 27.3 & 28.9 & 29.7 & 23.7 & $\mathrm{NA}^{\mathrm{b}}$ & 94.9 & NA & 56 \\
\hline OVCAR-3 & 26.9 & $>202$ & 25.3 & 31.9 & 31.8 & 27.7 & 30.6 & 81.7 & 71.6 & NA \\
\hline SK-OV-3 & 21.4 & $>202$ & 32.1 & 40.2 & 32 & 27.4 & 29.9 & 75.4 & 76.9 & 63.1 \\
\hline \multicolumn{11}{|l|}{ Prostat cancer } \\
\hline PX-3 & 15 & > 202 & 10.5 & 19 & 24.5 & 15.1 & 8.48 & NA & 35.9 & 38.2 \\
\hline PU-145 & 28.3 & $>202$ & 11.8 & 22.7 & 20.8 & NA & 5.1 & NA & 39.2 & 19.9 \\
\hline \multicolumn{11}{|l|}{ Liver cancer } \\
\hline HEPG2 & 23.6 & $>202$ & 18.8 & 29.7 & 40.5 & 37.8 & 45.9 & 4.3 & 84.2 & 77 \\
\hline
\end{tabular}

${ }^{a}$ Cell line growth inhibition with $>50 \%$ at a concentration of $10 \mathrm{mg} \mathrm{L}^{-1}$ was considered to be a noticeable activity. ${ }^{\mathrm{b}}$ NA: not active. Data are presented as the means Standard Deviation $( \pm \mathrm{SD})$ of three independent experiments. 
ent on the aryl-moiety or as a substituent on the phosphonate moiety, is usually associated with enhancement of the antitumor property, as indicated in compounds $3 \mathbf{a}, \mathbf{c}, \mathbf{4} \mathbf{a}$ and in $4 \mathrm{e}$ and $4 \mathrm{~g}$. In contrast to the antibiotic results, the data showed that the $\beta$-aminophosphonates $3 \mathbf{a}$ and $\mathbf{c}$ possess higher activity than their cyclic thiadiazole-counterparts $4 \mathbf{a}$ and $\mathbf{c}$. In general, compounds $3 \mathbf{a}$, in particular $4 \mathbf{e}$ and $\mathbf{4 g}$ showed more significant antitumor activity against tested carcinoma cell lines than the standard drug adriamycin. However, no straight correlation between the tumor activity and antibiotic efficacy of $\beta$-aminophosphonates and thiadiazoles or thiadiazines was found. This result is not surprising, since the targets of these two activities should be different. Further, the observed antibacterial activity, albeit weak, can be the result of non-specific cytotoxic effects (e.g., 6a and 8a), since bacteria can be killed in many ways.

\section{CONCLUSIONS}

We have developed a simple and convenient procedure for the preparation of a range of $\beta$-aminophosphonates 3a-h, fused-thiadiazole-5-methylphosphonates $4 \mathbf{a}-\mathbf{h}$ and thiadiazinephosphonate derivatives from readily prepared 4-(4-(arylideneamino)-4H-1,2,4-triazole-3-thiols $\mathbf{1} / \mathbf{2}$. The antimicrobial evaluation showed that the most active compounds are the fused thiadiazole-phosphonates $\mathbf{4 a}, \mathbf{c}, \mathbf{e}$ and $\mathbf{g}$, which inhibited the growth of Gram-negative and Gram-positive bacteria. On the other hand, the order of the antitumor properties for the tested selected compounds is: $3 a>3 c(\beta$-aminophosphonates) $>4 a>4 e>4 c>$ $4 \mathbf{g}$ (thiadiazolemethylphosphonates) $>6 \mathbf{a}>\mathbf{8 a}$ (thiadiazine-phosphonates).

Acknowledgments. - The authors thank the National Research Centre, Dokki, Cairo, Egypt (project 10010101) for financial support. The authors are also thankful to the Central Lab, School of Pharmacy, Alexandria University, Egypt, for the antimicrobial evaluation and the National Cancer Institute, NY, USA, for carrying out the antitumor screening and obtaining the culture cell lines.

Supporting information. - Computer prediction list of the biological activity of new compounds and positive standards is available as supplementary material from the corresponding author upon request through Professor Abdou, W. M.: wabdou@link.net.

\section{REFERENCES}

1. W. E. Dismukes, Antifungal therapy: Lessons learned over the past 27 years, Clin. Infect. Dis. 42 (2006) 1289-1296; DOI: 10.1086/503043.

2. R. A. Smith, V. Cokkinides and O. W. Brawley, Cancer screening in the United States, a review of current American Cancer Society guidelines and issues in cancer screening, Cancer J. Clin. 59 (2009) 27-41; DOI: 10.3322/caac.20008.

3. J. B. Bremner, J. I. Ambrus and S. Samosorn, Dual action-based approaches to antibacterial agents, Curr. Med. Chem. 14 (2007) 1459-1477; DOI: 10.2174/092986707780831168.

4. C. Hubschwerlen, J. L. Specklin, C. Sigwalt, S. Schroeder and H. H. Locher, Design, synthesis and biological evaluation of oxazolidinone-quinolone hybrids, Bioorg. Med. Chem. 11 (2003) 2313-2319; DOI: 10.1016/S0968-0896(03)00083-X.

5. A. K. Jordao, V. F. Ferreira, E. S. Lima, M. C. de Souza, E. C. Carlos, H. C. Castro, R. B. Geraldo, C. R. Rodrigues, M. C. Almeida and A. C. Cunha, Synthesis, antiplatelet and in silico evaluations of novel N-substituted- phenylamino-5-methyl-1H-1,2,3-triazole-4-carbohydrazides, Bioorg. Med. Chem. 17 (2009) 3713-3719; DOI: 10.1016/j.bmc.2009.03.053. 
6. V. Calderone, I. Giorgi, O. Livi, E. Martinotti, E. Mantuano, A. Martelli and A. Nardi, Benzoyl and/ or benzyl substituted 1,2,3-triazoles as potassium channel activators, VIII, Eur. J. Med. Chem. 40 (2005) 521-528; DOI: 10.1016/ j.ejmech.2005.01.010.

7. R. F. Pratt, Inhibition of class A beta-lactamase by a specific phosphonate monoester, Science $\mathbf{2 4 6}$ (1989) 917-919; DOI: 10.1126/science.2814513.

8. P. Duncanson, Y. K. Cheong, M. Motevalli and D. V. Griffiths, Novel approach to isoindolo[2,1-a] indol-6-ones, Org. Biomol. Chem. 10 (2012) 4266-4279; DOI: 10.1039/C2OB25314C.

9. S. Crotty, D. Maag, J. J. Arnold, W. Zhong, J. Y. N. Lau, Z. Hong, R. Andino and C. E. Cameron, The broad spectrum antiviral ribonucleotide, ribavirin, is an RNA virus mutagen, Nature Med. 6 (2000) 1375-1379; DOI: 10.1038/82191.

10. N. Mauras, K. Bishop, D. Merinbaum, U. Emeribe, F. Agbo and E. Lowe, Pharmacokinetics and pharmacodynamics of anastrozole in pubertal boys with recent-onset gynecomastia, J. Clin. Endocrinol. Metab. 94 (2009) 2975-2978; DOI: 10.1210/jc.2008-2527.

11. W. M. Abdou, M. D. Khidre and R. E. Khidre, Application of phosphonyl carbanions to highly regioselective synthesis of some diazaphospholes and pyrazolinyl phosphonates, Eur. J. Med. Chem. 44 (2009) 526-532; DOI: 10.1016/j. ejmech.2008.03.032.

12. W. M. Abdou, N. A. Ganoub and E. Sabry, Synthesis of antimicrobial N-phthaloyl-alanyl-derived amidophosphates and triazoles, Z. Naturforsch. 46b (2009) 1057-1064.

13. W. M. Abdou, A. A. Sediek and M. D. Khidre, An efficient method for the synthesis of spiro and fused N-heterocyclic phosphor esters. Reactions of triketoindan-2-oxime with $\alpha$-phosphonyl carbanions, Monatsh. Chem. 139 (2008) 617-623; DOI: 10.1007/s00706-007-0806-z.

14. W. M. Abdou, R. F. Barghash and A. A. Sediek, Design of new arylamino-2-ethane-1,1-diyl- and benzoxazole-2-methylene-bisphosphonates $v s$ cytotoxicity and chronic inflammation diseases. From hydrophobicity prediction to synthesis and biological evaluation, Eur. J. Med. Chem. 57 (2012) 362-372; DOI: 10.1016/j. ejmech.2012.09.032.

15. W. M. Abdou, R. F. Barghash and M. S. Bekheit, Carbodiimides in the synthesis of enamino- and $\alpha$-aminophosphonates as peptidomimetics of analgesic/antiinflam-matory and anticancer agents, Arch. Pharm. Chem. Life Sci. 345 (2012) 884-895; DOI: 10.1002/ardp.201200142.

16. A. A. Kamel, A. Geronikaki and W. M. Abdou, Inhibitory effect of novel $S, N$-bisphosphonates on some carcinoma cell lines, osteoarthritis and chronic inflammation, Eur. J. Med. Chem. 51 (2012) 239-249; DOI: 10.1016/j.ejmech. 2012.02.047.

17. C. H. Da Silva, V. B. Da Silva, J. Resende, P. F. Rodrigues, F. C. Bononi, C. G. Benevenuto and C. A. Taft, Computer-aided drug design and ADMET predictions for identification and evaluation of novel potential farnesyl- transferase inhibitors in cancer therapy, J. Mol. Graph. Model. 28 (2010) 513-523; DOI: 10.1016/j. jmgm.2009.11.011.

18. A. A. Lagunin, O. A. Gomazkov, D. A. Filimonov, T. A. Gureeva, E. A. Dilakyan, E. V. Kugaevskaya, Y. E. Elisseeva, N. I. Solovyeva and V. V. Poroikov, Computer-aided selection of potential antihypertensive compounds with dual mechanism of action, J. Med. Chem. 46 (2003) 3326-3332; DOI: $10.1021 / \mathrm{jm} 021089 \mathrm{~h}$.

19. Y. Bai, G. Zhao, C. Li, S. Zhao and Z. Shi, Microwave-enhanced reactions of 4-amino-5-mercapto1,2,4-triazoles with benzoyl chloride and aromatic aldehydes, Synth. Commun. 38 (2008) 33113319; DOI: 10.1080/00397910802136649.

20. N. Al-Awadi, Y. Ibrahim, K. Kaul and H. Dib, Gas-phase elimination reactions of 4-arylideneimino-1,2,4-triazol-3(2H)-ones and their 3(2H)-thione analogues, J. Phys. Org. Chem. 14 (2001) 521-525; DOI: $10.1002 /$ poc.383.

21. C. Perez, M. Pauli and P. Bazerque, An antibiotic assay by the agar well diffusion method, Acta Biol. Med. Exp. 15 (1990) 113-115. 
W. M. Abdou et al.: Design, synthesis and pharmacological screening of $\beta$-amino-, thiadiazole/thiadiazine-phosphonate based triazole motifs as antimicrobial/cytotoxic agents, Acta Pharm. 64 (2014) 267-284.

22. A. C. Scott, Laboratory Control of Antimicrobial Therapy, in Mackie and McCartney Practical Medical Microbiology (Eds. J. G. College, J. P. Duguid, A. G. Fraserand and B. P. Marmion), 13 ${ }^{\text {th }}$ ed., Churchill Livingstone, London 1989, pp. 161-181.

23. Clinical and Laboratory Standards Institute (CLSI), Performance Standards for Antimicrobial Susceptibility Testing, 17 ${ }^{\text {th }}$ informational supplement, CLSI document M100-S17, Wayne (PEN) 2007.

24. T. Kitamura, M. Itoh, T. Noda, M. Matsuura and K. Wakabayashi, Combined effects of cyclooxygenase-1 and cyclooxygenase-2 selective inhibitors on intestinal tumorigenesis in adenomatous polyposis coli gene knockout mice, Int. J. Cancer 109 (2004) 576-580; DOI: 10.1002/ijc.20012.

25. M. R. Boyd and K. D. Paull, Some practical considerations and applications of the national cancer institute in vitro anticancer drug discovery screen, Drug Dev. Res. 34 (1995) 91-109; DOI: 10.1002/ ddr.430340203.

26. J. March, Advanced Organic Chemistry, Reactions, Mechanisms, and Structures, $3^{\text {rd }}$ ed., Wiley, New York 1985, pp. 82-140.

27. J. Vinsová, K. Cermáková, A. Tomecková, M. Cecková, J. Jampílek, P. Cermák, J. Kunes, M. Dolezal and F. Staud, Synthesis and antimicrobial evaluation of new 2-substituted 5,7-di-tert-butylbenzoxazoles, Bioorg. Med. Chem. 14 (2006) 5850-5865; DOI: 10.1016/j.bmc.2006.05.030.

28. E. S. T. Ali, Synthesis and antibacterial activity of some new thiadiaza/triaza-phospholes, thiadiaza/triaza/tetraazaphosphinines and thiadiaza/tetraza-phosphepines containing 1,2,4-triazinone moiety, Eur. J. Med. Chem. 44 (2009) 4539-4546; DOI: 10.1016/j.ejmech.2009.06.022.

29. H. Lee and R. G. Harvey, 2,3-Dichloro-5,6-dicyano-1,4-benzoquinone (DDQ) in acetic acid, a convenient new reagent for the synthesis of aryl ketones and aldehydes via benzylic oxidation, J. Org. Chem. 53 (1988) 4587-4589; DOI: 10.1021/jo00254a035. 